The definitive version is available at www.blackwell-synergy.com

Review of Economic Studies, Vol. 70, Iss. 3, pg 461-487 (2003) or at

http://www.jstor.org/stable/i369975

\title{
Endogenous Debt Constraints in Lifecycle Economies*
}

\author{
Costas Azariadis, $\mathrm{UCLA}^{\dagger}$ \\ and \\ Luisa Lambertini, UCLA ${ }^{\ddagger}$ \\ First draft - May 4, 2000 \\ Final draft — September 13, 2002
}

\begin{abstract}
We characterize competitive equilibria with perfect foresight in a deterministic, three-period pure-exchange overlapping generations economy with perfect information and no commitment to loan contracts. Commitment is replaced by an enforcement mechanism that excludes defaulters from asset markets for one period. For hump-shaped endowment profiles, young individuals face endogenous debt constraints that ration current consumption. Changes in current and future yields affect these constraints, inducing an additional income effect on rationed household demand that makes current and future consumption complements. This mechanism can lead to multiple steady states, persistent indeterminacy and regime switching. We show that sensitivity to shocks and complex dynamic behavior are consistent with endogenous debt limits but not with exogenous liquidity constraints.
\end{abstract}

JEL Classification: E32, D91, D52

*This paper grew out of earlier work by Luisa Lambertini [29]: "Borrowing and Lending without Commitment and with Finite Life.". Earlier versions of this paper were presented under a slightly different title at Princeton, Stanford, the SED Meeting 1999, DELTA, UCLA, UC Riverside, University of Rome, University of Texas-Austin and the NBER General Equilibrium Meeting 2000. We are indebted to Alberto Bennardo, Michael Woodford, Joseph Zeira, three anonymous referees and an editor for useful comments.

${ }^{\dagger}$ Costas Azariadis, Department of Economics, University of California, Los Angeles, CA 900951477, USA. E-mail: azariadi@ucla.edu

${ }^{\ddagger}$ Luisa Lambertini, Department of Economics, University of California, Los Angeles, CA 900951477, USA. E-mail: luisa@econ.ucla.edu 


\section{Introduction}

In economies with infinitely-lived consumers and uncertainty, endogenous debt constraints describe how markets respond when sellers of future claims are unable to commit to loan or insurance contracts they can afford. Recent research has found much use for this concept in investigating the fundamental theorems of welfare economics (Kehoe and Levine [24]), anomalies in asset returns (Alvarez and Jermann [3]), and international risk sharing (Kehoe and Perri [22]). This paper examines the complementary question of endogenous debt constraints in a model with finite lives and without uncertainty. We characterize the set of stationary and dynamic competitive equilibria under perfect foresight and find that binding constraints lead to complementarity between current and future consumption. This mechanism can result in multiple steady states and indeterminacy with many degrees of freedom or in the non-existence of competitive equilibria.

We investigate a pure-exchange deterministic economy with perfect information and one perishable consumption good. Overlapping generations of homogeneous households who live for three periods inhabit this economy. There is no fiat money or storage technology; the only way to transfer consumption from one period to another is by borrowing or lending.

A crucial feature of our setting is that individuals cannot commit to their contracts. Following default, harmed creditors can garnish the debtor's assets and loan revenues but cannot seize her private endowments. Since no defaulter will rationally choose to lend in these conditions, default is necessarily followed by the defaulter's abstention from the loan market. Under perfect information, lenders know how much borrowers will voluntarily repay and will not lend in excess of that. Therefore, equilibrium allocations will be constrained to remove all incentives to default.

With hump-shaped endowment profiles, young agents will typically want to borrow and middle-aged ones will want to lend. Young agents who cannot commit to repayment may face binding debt constraints that tie their consumption to their income. The key issue is how debt limits reflect agent characteristics and market conditions.

Debt limits are low for households with low discount factor, flat endowment profile and/or high intertemporal elasticity of substitution. Agents of that type value consumption smoothing and access to the intertemporal credit market so slightly that they have no incentive to repay any borrowed amount. Autarky turns out to be the only stationary allocation of this economy and no dynamic competitive equilibrium exists for all initial distributions of debt other than zero.

Constraints are more generous for households with a high discount factor, peaky endowment profiles and/or low intertemporal elasticity of substitution. These agents put a high value on smoothing consumption between middle and old age and, therefore, on being able to lend when their endowment is high. Agents with such characteristics 
value market participation highly and have a strong incentive to repay. In these circumstances, some borrowing takes place and lifecycle consumption becomes smoother than income.

How much borrowing takes place depends a great deal on expected future loan yields. In particular, an increase in future yields makes future lending more attractive, thereby raising the amount young agents will voluntarily pay back. As a result, agents borrow more in youth, lend more in middle-age and consume more in both youth and old age. The strong income effect generated by changes in future yields makes the demand for loans by the young non-monotonic and becomes the source of multiple equilibria and indeterminacy. Youth and old-age consumption are complements for rationed individuals, even though they may be highly substitutable in their utility function.

The outcome is two non-autarkic, saddle-point stable steady states: one unconstrained and one constrained. Which one prevails depends on how much the initial middle-aged cohort owes to the initial old. For intermediate values of the initial debt load, the economy converges to the unconstrained steady state where debt constraints are slack, interest rates are high and lifecycle consumption is smoothed exactly as under commitment. For low initial debt loads, the economy converges to the constrained steady state with tight debt contraints, low interest rates and limited borrowing that hampers consumption smoothing. Autarky is an unstable steady state that can be reached only from a zero initial debt.

Non-autarkic economies may suffer from sequential indeterminacy, a severe form of multiple equilibria with several degrees of freedom. For initial debt loads in certain ranges, both constrained and unconstrained equilibria are feasible. These environments can easily generate complex dynamic behavior, with excess sensitivity of yields and consumption to shocks, in which the economy switches regimes from constrained to unconstrained, or vice versa, in response to a small perturbation in income or wealth or because of changing expectations about future yields.

The key feature of our work is that households are finitely lived, so that credit market exclusion is temporary. Market yields prevailing during the time of exclusion from market activity greatly affect the consumption pattern of credit-rationed traders. It is the yields prevailing in middle-age, when an agent may default on her debt, that determine the agent's eagerness to lend and, therefore, to repay her youthful debts. This particular feature distinguishes what we do here from related research in environments with infinitely lived agents and limited contract enforceability. In Kehoe and Levine [24], [25] and Alvarez and Jermann [3], the punishment for default lasts forever so that changes in any single future market yield are unlikely to change borrowing limits significantly. On the other hand, in Bewley [10] and Bulow and Rogoff [11], default does not preclude future lending; hence, there is no punishment for default and, in either case, no borrowing in equilibrium. 
Our economy also differs substantially from related models with exogenous liquidity constraints that permit loans up to a fixed fraction of the remaining lifecycle endowment, as in Jappelli and Pagano [21]. Liquidity constraints diminish individual loan demand by strengthening the substitution effect of interest-rate changes. The outcome is a unique equilibrium that converges to a relatively low steady-state yield. Lifecycle models with these constraints and fiat money exhibit a standard initial-conditions indeterminacy and straightforward dynamic properties.

Our model has three testable implications. First, it predicts a positive correlation between consumption and income. This is consistent with the findings of many empirical papers that use aggregate or PSID data and find that consumption is excessively sensitive to income. ${ }^{1,2}$ Second, unlike other models with exogenous or no debt constraints, our model predicts a positive relationship between current consumption and expected future interest rates for rationed agents. Third, we predict a positive relationship between current consumption and intertemporal consumption substitutability. Young individuals with a rising earnings profile are likely to face binding debt constraints that tie consumption to income and reduce intertemporal substitutability. Middle-age individuals face a falling earnings profile that implies slack debt constraints, considerable smoothing of consumption between middle and old age, and high intertemporal substitutability. ${ }^{3}$

The rest of the paper is organized as follows. Section 2 lays out the economic environment. Some basic property of equilibria with commitment are reviewed in section 3. Section 4 describes the corresponding lifecycle economy without commitment; equilibria are studied in Section 5 while Section 6 characterizes dynamic equilibria. Section 7 compares our results with models of exogenous debt limits; Section 8 connects our findings with related literature. Finally, Section 9 discusses extensions and points out potential implications for asset prices.

\section{The economic environment}

We study a closed, pure-exchange economy of overlapping cohorts with a typical lifecycle $L=3$ periods that is well suited for exploring lifecycle issues in environments

\footnotetext{
${ }^{1}$ See Flavin [17], Hansen and Singleton [19] [20], Mankiw et al. [30] and Campbell and Mankiw [12] for evidence using aggregate data; Zeldes [35] and Hall and Mishkin [18] for evidence using PSID data.

${ }^{2}$ These findings, however, have been questioned by a number of authors. For example, Attanasio and Weber [7] show that excess sensitivity in macro data can be attributed to aggregation bias; Runkle [32] and Altonji and Siow [2] find weak or no evidence of excess sensitivity in PSID data.

${ }^{3}$ In a lifecycle model without debt constraints, Attanasio and Browning [8] use cohort-mean data from the U.K. Family Expenditure Survey and find that the elasticity of intertemporal substitution increases with the level of consumption.
} 
with heterogeneous agents. For simplicity, we abstract from production, uncertainty and finite lifecycles ${ }^{4}$ of length $L>3$. Time is indexed by $t=1,2, \ldots$ and cohorts by $v=-1,0,1, \ldots$. Members of cohort $v$ are identical, and are double-indexed by a cohort superscript and a calendar-time subscript. There are $N_{v}=(1+n)^{v}$ individuals in cohort $v \geq 1$, with $n>-1$. Cohorts $v=-1,0$ are transitional with lifecycles of 1 and 2 periods respectively. All subsequent cohorts $v \geq 1$ live three periods: youth at $t=v$, middle age at $t=v+1$, old age at $t=v+2$.

Endowments and preferences are common knowledge. In particular, the endowment profile of a generation- $t$ household is

$$
y^{t}= \begin{cases}y_{2} \geq 0 & \text { for } t=-1 \\ \left(y_{1}, y_{2}\right) \in \mathcal{R}_{+}^{2} & \text { for } t=0 \\ \left(y_{0}, y_{1}, y_{2}\right) \in \mathcal{R}_{+}^{3} & \text { for } t \geq 1\end{cases}
$$

The corresponding utility functions at the beginning of economic life are

$$
V_{t}^{t}= \begin{cases}c_{1}^{-1} & \text { for } t=-1 \\ u\left(c_{1}^{0}\right)+\beta u\left(c_{2}^{0}\right) & \text { for } t=0 \\ \sum_{s=0}^{2} \beta^{s} u\left(c_{t+s}^{t}\right) & \text { for } t \geq 1\end{cases}
$$

where $c^{t}=\left(c_{t}^{t}, c_{t+1}^{t}, c_{t+2}^{t}\right) \in \mathcal{R}_{+}^{3}$ is the household consumption vector, $\beta>0$ is the subjective discount factor, and $u: \mathcal{R}_{+} \rightarrow \mathcal{R}$ is a twice continuously differentiable, strictly increasing concave function.

Households of generation $t=-1,0,1, \ldots$ maximize lifetime utility given the vector of yields $\left(R_{t}, R_{t+1}\right)$. If they repay their loans, lifecycle budget constraints have the usual form

$$
\begin{aligned}
c_{t+2}^{t} & \leq y_{2}+(1+n) w_{1} \quad \text { for } t=-1 \\
c_{t+1}^{t}+\frac{c_{t+2}^{t}}{R_{1}} & \leq y_{1}-w_{1}+\frac{y_{2}}{R_{1}} \quad \text { for } t=0 \\
c_{t}^{t}+\frac{c_{t+1}^{t}}{R_{t}}+\frac{c_{t+2}^{t}}{R_{t} R_{t+1}} & \leq y_{0}+\frac{y_{1}}{R_{t}}+\frac{y_{2}}{R_{t} R_{t+1}} \quad \text { for } t \geq 1 .
\end{aligned}
$$

In these expressions $R_{t}=1+r_{t}$ is the yield on a loan of one consumption unit lent out at $t$ and payable at $t+1$. The parameter $w_{1} \in\left[-y_{2}, y_{1}\right]$ defines initial conditions for our economy; it specifies the value of principal and interest owed by each household of cohort $v=0$ to a counterpart in cohort $v=-1$.

\footnotetext{
${ }^{4} L=3$ is an assumption we make for analytical tractability. In overlapping generation economies with collateral income or a commitment technology (Kehoe and Levine [23]; Azariadis, Bullard and Ohanian [9]) we know that equilibria with $L=3$ have similar qualitative properties (existence, convergence, determinacy) to equilibria with $L>3$.
} 
Letting $b^{t}=\left(b_{t}^{t}, b_{t+1}^{t}\right) \in \mathcal{R}^{2}$ be the vector of claims by a member of cohort $t$ at the end of periods $(t, t+1)$, we may rewrite the lifecycle constraint (5), under the assumption that loans are repaid, as a set of three period-by-period budget constraints, that is,

$$
\begin{gathered}
y_{0}=c_{t}^{t}+b_{t}^{t}, \\
y_{1}+R_{t} b_{t}^{t}=c_{t+1}^{t}+b_{t+1}^{t}, \\
y_{2}+R_{t+1} b_{t+1}^{t}=c_{t+2}^{t} .
\end{gathered}
$$

These apply, respectively, to youth, middle age, and old age.

Given the vector of yields $\left(R_{t}\right)_{t=1}^{\infty}$, individual asset demands $\left(b_{t}^{t}, b_{t+1}^{t}\right)_{t=0}^{\infty}$ are influenced by the discount factor $\beta$, the utility function $u$, the endowment profile $\left(y_{0}, y_{1}, y_{2}\right)$, and the enforcement mechanism for loan contracts. If endowments consist of collateral goods, then a relatively inexpensive legal mechanism creates an environment of commitment in which households do not default on any loans they can afford to repay. For example, a mechanism that allows creditors to seize publicly known endowments of individual debtors reduces the debtors' incentive to default. Environments without collateral income cannot set up this enforcement technology; they must rely instead on the self-interest of borrowers to enforce repayment promises. In this setting, individual rationality constraints (IRC's henceforth) on borrowers must supplement lifecycle budget constraints.

To simplify the set of competitive equilibria, we restrict the endowment and preferences to ensure that equilibrium is unique in an economy with commitment but without money or public debt. This requires

Assumption 1 In the economy with commitment, all dated goods are normal and gross substitutes at all prices.

For a CES utility function with elasticity of intertemporal substitution equal to $\sigma>0$, a sufficient condition for Assumption 1 to be satisfied is $\sigma \geq 1$. If $0<\sigma<1$, then either $y_{1}>y_{0} \geq y_{2}$ or $y_{1}>y_{2}>y_{0}$ and $n<0$ is a sufficient condition. Gross substitutability trivially means that consumption demand in any period is an increasing function of the price of consumption in any other period within the household's lifespan. Further, asset demands in a commitment economy are increasing functions of loan yields. Specifically, we have

Lemma 1 Let $\left\{b_{t}^{t}, b_{t+1}^{t}\right\}=\left\{B\left(R_{t}, R_{t+1}\right), \hat{B}\left(R_{t}, R_{t+1}\right)\right\}$ be the list of asset demands with commitment for cohort $t \geq 1$, that is, $\left(b_{t}^{t}, b_{t+1}^{t}\right)=\arg \max V_{t}^{t}$ s.t. (6), (7), (8) and $c^{t}=\left(c_{t}^{t}, c_{t+1}^{t}, c_{t+2}^{t}\right) \in \mathcal{R}_{+}^{3}$. Then

1. The functions $B: \mathcal{R}_{+}^{2} \rightarrow \mathcal{R}$ and $\hat{B}: \mathcal{R}_{+}^{2} \rightarrow \mathcal{R}$ are continuously differentiable and increasing. 
2. $\hat{B}\left(R_{t}, R_{t+1}\right)=z\left(R_{t+1}, w_{t+1}\right)$ where $w_{t+1}=-R_{t} B\left(R_{t}, R_{t+1}\right)$ is the debt of a member of cohort $t$ to cohort $t-1$, payable at $t+1$; and $z(R, w) \equiv \arg \max _{z}\left\{u\left(y_{1}-w\right.\right.$ $\left.-z)+\beta u\left(y_{2}+R z\right)\right\}$ is the asset position of a middle-aged individual with debt load $w$ when the expected loan yield is $R>0$.

We conclude that, in a commitment economy, the community (or aggregate) demand for assets at any time $t \geq 2$,

$$
B^{u}\left(R_{t-1}, R_{t}, R_{t+1}\right)=B\left(R_{t}, R_{t+1}\right)+\frac{1}{1+n} \hat{B}\left(R_{t-1}, R_{t}\right)
$$

is also an increasing function of the vector $\left(R_{t-1}, R_{t}, R_{t+1}\right)$.

\section{Commitment equilibria}

We review first an environment in which loan contracts are enforceable by binding legal commitments or by a costless technology based on collateral income. Consumption loans are the only store of value in this economy; a competitive equilibrium is a list $\left(c_{t}^{t}, c_{t}^{t-1}, c_{t}^{t-2}, R_{t}\right)_{t=1}^{\infty}$ which satisfies the budget constraints (6) - (8) and makes the community demand for assets, defined in equation (9), vanish at each date $t \geq 1$. Equilibria in this economy have straightforward properties that mimic those of standard atemporal economies. Assuming gross substitutes, there is a unique steady state, and a unique dynamic equilibrium that converges to the steady state.

More formally, equilibria are solutions to the difference equation

$$
B^{u}\left(R_{t-1}, R_{t}, R_{t+1}\right)=0, \quad t \geq 2
$$

for a given initial restriction on $\left(R_{1}, R_{2}\right)$ that is implied by market clearing at $t=1$ for the initial debt load, $w_{1}$, of cohort $v=0$ to cohort $v=-1$. This is a secondorder difference equation that we can easily decompose into a system of two first-order equations if we use as state variable the sequence $\left(R_{t}, w_{t}\right)$ of yields and debt loads:

$$
\begin{gathered}
B\left(R_{t}, R_{t+1}\right)+\frac{1}{1+n} z\left(R_{t}, w_{t}\right)=0, \quad t \geq 1 \\
(1+n) w_{t+1}=R_{t} z\left(R_{t}, w_{t}\right), \quad t \geq 1 \\
w_{1} \geq-y_{2} \text { given. }
\end{gathered}
$$

This system consists of the market-clearing condition (11), the evolution of the debt load (12), and the initial condition (13).

Solutions to equation (10) or to the dynamical system (11) to (13) are available from Kehoe and Levine [23], Kehoe, Levine, Mas-Colell and Woodford [26], and from Azariadis, Bullard and Ohanian [9] who study OLG economies with arbitrary lifecycles $L \geq 2$. Without proofs, we summarize their results in 


\section{Theorem 1}

1. If Assumption 1 is satisfied, there is at most one stationary equilibrium with commitment, $\left(w_{u}^{*}, R_{u}^{*}\right)$.

2. If a steady state exists, then for each initial condition $w_{1} \geq-y_{2}$ such that $z\left(R_{1}, w_{1}\right) \geq-y_{0}$, there is a unique equilibrium sequence that converges nonmonotonically to $\left(w_{u}^{*}, R_{u}^{*}\right)$.

The logic of this result is simple. Steady states are zeros of the increasing function $B^{u}(R, R, R)$; there can be at most one such zero. Furthermore, sequences converging to $R_{u}^{*}$ must do so in oscillatory fashion.

To prove that a stationary equilibrium exists in which young individuals borrow from middle-age ones, we assume that the endowment profile is sufficiently "peaky". In particular, we have

Assumption 2 Let $\bar{R}_{0}=u^{\prime}\left(y_{0}\right) /\left(\beta u^{\prime}\left(y_{1}\right)\right)$ be the marginal rate of substitution at the endowment point $\left(y_{0}, y_{1}\right)$, and $\bar{R}_{1}=u^{\prime}\left(y_{1}\right) /\left(\beta u^{\prime}\left(y_{2}\right)\right)$ be the corresponding marginal rate of substitution at the endowment point $\left(y_{1}, y_{2}\right)$. Then

$$
\bar{R}_{1}<1+n<\bar{R}_{0}
$$

For a CES utility function, equation (14) becomes $\left(y_{2} / y_{1}\right)^{1 / \sigma}<\beta(1+n)<\left(y_{1} / y_{0}\right)^{1 / \sigma}$. A hump-shaped income profile satisfies both Assumption 2 and Assumption 1. This leads directly to the following result:

Theorem 2 Let $D_{u}(R)=B^{u}(R, R, R)$ be the community asset demand at a constant yield $R>0$. If Assumptions 1 and 2 hold, then

1. There is a unique steady state $R_{u}^{*} \in\left(\bar{R}_{1}, \bar{R}_{0}\right)$, and it is a saddle.

2. This state is dynamically efficient if, and only if, $D_{u}(1+n) \leq 0$.

3. $B\left(R_{u}^{*}, R_{u}^{*}\right)<0<\hat{B}\left(R_{u}^{*}, R_{u}^{*}\right)$, that is, the young borrow from the middle-aged when the loan yield is $R_{u}^{*}$.

4. Starting from any initial debt load $w_{1} \neq w_{u}^{*}$, the equilibrium sequence $\left(w_{t}^{*}, R_{t}^{*}\right)$ lies on a continuous one-dimensional manifold $\psi_{u}$.

Figure 1 illustrates the equilibrium in the commitment economy with constant population. Non-negative equilibrium consumption requires that the equilibrium manifold $R_{t}=\psi_{u}\left(w_{t}\right)$ be defined for all debt loads such that

$$
z\left(R_{t}, w_{t}\right) \geq-y_{0}
$$




$$
w_{t} \geq-y_{2}
$$

Initial debt loads lower than $-y_{2}$ cannot be repaid by old individuals and violate (16). Since middle-age borrowing from the young cannot exceed the young's endowment, as stated in (15), there is a lower bound on the interest rate for each initial debt load. The equilibrium manifold $\psi_{u}$, which is defined for combinations of $\left(w_{t}, R_{t}\right)$ that satisfy $(15)$ and (16), describes the unique solution sequence $\left(w_{t}^{*}, R_{t}^{*}\right)$ that converges to $\left(w_{u}^{*}, R_{u}^{*}\right)$ for a given initial condition $w_{1} \in\left[-y_{2}, y_{1}\right]$. The double arrows indicate that convergence to the unique steady state is non-monotonic.

\section{[FIGURE 1 ABOUT HERE]}

Suppose, for example, that $\beta=1, u(c)=\log c, n=0, y^{t}=(e, 1, e)$ with $0<e<1$. Then

$$
b_{t}^{t}=\frac{1}{3}\left(2 e-\frac{1}{R_{t}}-\frac{e}{R_{t} R_{t+1}}\right), \quad b_{t+1}^{t}=\frac{1}{2}\left(1+R_{t} b_{t}^{t}-\frac{e}{R_{t+1}}\right),
$$

and the steady state is $\left(w_{u}^{*}, R_{u}^{*}\right)=((1-e) / 3,1)$.

\section{Debt-constrained asset demands}

This section and the next one describe stationary competitive equilibria in an environment in which individual endowments cannot be used as collateral ${ }^{5}$ and households cannot credibly commit to repay loans when doing so is not in their own interest. The absence of commitment means that borrowing against future income will typically be limited more tightly than lifecycle budget constraints permit, in a manner that reflects market conditions and individual agent characteristics.

As in Kehoe and Levine [24] [25], we assume that the legal environment has the following characteristics: all information, including default, is public; there are no restrictions on saving, as agents can lend at any point in life, even after default. In the event of default, the defaulter's private endowments cannot be seized while all her assets, including current and future loan revenues up to the default amount, can be garnished by harmed creditors. Hence, this rule of law is more sophisticated than bilateral punishment.

The legal environment of our model means that the private cost of default is the forgone gain from trading in the intertemporal market for the rest of the agent's life. This feature does not rest on any restriction on lending/saving, as individuals are allowed to lend after they default; rather, they have no incentive to do so because public information and the rule of law make the revenues from current and future loan

\footnotetext{
${ }^{5}$ Kiyotaki and Moore [27] construct a model of economic volatility that exploits the interaction between collateral and borrowing constraints. See section 9 for details.
} 
contracts vulnerable to claims by prior debtors. Similarly, an individual can borrow after default, but she will not find any lender ready to do so because middle-aged individuals have no incentive to repay their loans. In this environment, default does not occur in equilibrium because fully informed rational lenders will never lend more than borrowers are willing to repay. ${ }^{6}$

To understand the factors affecting debt limits, we study the optimal lending decision for a member of cohort $t$ who cannot credibly commit to repay. This decision is the solution to the following problem:

$$
\left\{b_{t}^{t}, b_{t+1}^{t}\right\}=\arg \max \sum_{s=0}^{2} \beta^{s} u\left(c_{t+s}^{t}\right),
$$

given the vector $\left(R_{t}, R_{t+1}\right)$ of yields, and subject to (6), (7), (8) and the IRC's:

$$
u\left(c_{t+1}^{t}\right)+\beta u\left(c_{t+2}^{t}\right) \geq u\left(y_{1}\right)+\beta u\left(y_{2}\right)
$$

and

$$
u\left(c_{t+2}^{t}\right) \geq u\left(y_{2}\right) .
$$

Individual rationality amounts to self-enforcement of loan contracts: it restricts lenders to offer contracts that the borrowers find preferable to autarky. The IRC (19) means that middle-aged individuals cannot borrow at all because market participation is of no value in the last period of life. An equivalent solvency constraint is

$$
b_{t+1}^{t} \geq 0 \text {. }
$$

Young households face the more complicated problem, illustrated in Figure 2, of choosing in middle age between default and continued trading. Young borrowers carry into middle age negative claims valued at $R_{t} b_{t}^{t}<0$, and a utility function $V_{t+1}^{t}=$ $u\left(c_{t+1}^{t}\right)+\beta u\left(c_{t+2}^{t}\right)$.

\section{[FIGURE 2 ABOUT HERE]}

Post-youth consumption will be autarkic, that is, $\left(c_{t+1}^{t}, c_{t+2}^{t}\right)=\left(y_{1}, y_{2}\right)$, which is point $\mathrm{A}$ in Figure 2, if the borrower chooses default and a zero subsequent asset position. Repayment of the loan permits continued market participation and accumulation of assets to provide for old age. In this case, given $\left(R_{t}, R_{t+1}\right)$ and the debt load $w_{t}=$ $-R_{t} b_{t}^{t}$, we have

$$
\begin{gathered}
\left(c_{t+1}^{t}, c_{t+2}^{t}\right)=\arg \max V_{t+1}^{t} \\
\text { subject } \quad \text { to } \quad c_{t+1}^{t}+\frac{c_{t+2}^{t}}{R_{t+1}} \leq y_{1}-w_{t}+\frac{y_{2}}{R_{t+1}}
\end{gathered}
$$

\footnotetext{
${ }^{6}$ In contrast, default is a socially useful institution in environments with private information (Dubey et al. [16], Araujo et al. [4]).
} 


$$
y_{2} \leq c_{t+2}^{t}
$$

Borrowers prefer the solution of (21) to autarky if, and only if, the debt load $w_{t}$ carried from youth into middle age is not too large relative to the expected future yield $R_{t+1}$. In terms of Figure 2, this is the case if the debt load $-R_{t} B_{y}^{c}$ does not exceed the horizontal distance between point A and point B. Sufficiently low expected rates of interest $R_{t+1}<\bar{R}_{1}$ will induce households to borrow in middle age, violating the oldage debt constraint (19) for that cohort. On the other hand, values of $R_{t+1}$ above the autarkic yield $\bar{R}_{1}$ allow young members of cohort $t$ to borrow within their IRC's. High current interest rates, $R_{t}$, reduce the borrowing limit $-B_{y}^{c}$, that is, the loan size that makes debtors indifferent between autarky and market participation.

A key point of figure 2 is that both the borrowing limit $-B_{y}^{c}$ and consumption in youth increase with the expected future yield $R_{t+1}$. High future yields lower the utility cost of repaying loans in middle age and, simultaneously, make saving for old age more attractive. Figure 2 shows that an increase in $R_{t+1}$ makes the budget line steeper, thereby increasing the borrowing limit $-B_{y}^{c}$. This means that the youthful consumption demand of a constrained individual is a decreasing function of the price of old-age consumption. This means that constrained consumers regard dated consumption goods as complements rather than substitutes, and leads to

Theorem 3 If Assumptions 1 and 2 hold, then consumption in youth and old age are gross substitutes if debt constraints are slack, complements if debt constraints are binding.

Loss of intertemporal substitutability also means that asset demand ceases to be monotonically increasing in yields, so that the uniqueness of equilibrium may be destroyed. Sections 5 and 6 , in particular, show that the lack of commitment destroys the uniqueness of equilibrium.

Figure 2 also implies that the debt constraint on the young is

$$
b_{t}^{t} \geq B_{y}^{c}\left(R_{t}, R_{t+1}\right) .
$$

Properties of the borrowing limit, $-B_{y}^{c}$, are collected in the following result which we prove in Appendix A.1.

\section{Lemma 2}

1. $B_{y}^{c}$ is continuously differentiable.

2. There exists a number $\bar{y}_{1} \in\left(0, y_{1}\right]$ and a decreasing function $f:\left[\bar{R}_{1}, \infty\right) \rightarrow$ $\left[-y_{1}, 0\right]$ such that

$$
B_{y}^{c}\left(R_{t}, R_{t+1}\right)=f\left(R_{t+1}\right) / R_{t}
$$


3. $f^{\prime}(R)=-z[R,-f(R)] / R$ and $f\left(\bar{R}_{1}\right)=0$.

4. $f(R) \rightarrow-\bar{y}_{1}$ as $R \rightarrow \infty$.

Asset demands for the economy without commitment are now easy to define in a way that respects the IRC's (18) and (19). Specifically,

$$
\begin{gathered}
b_{t}^{t}=\max \left\{B\left(R_{t}, R_{t+1}\right), f\left(R_{t+1}\right) / R_{t}\right\} \\
b_{t+1}^{t}=\max \left\{0, z\left(R_{t+1},-R_{t} b_{t}^{t}\right)\right\} .
\end{gathered}
$$

Competitive equilibria correspond to a sequence $\left(w_{t}, R_{t}\right)_{t=1}^{\infty}$ of debt loads and loan yields which satisfy the asset demand schedules (24) and (25), an initial condition $w_{1} \in\left(0, y_{1}\right)$, and the market clearing condition

$$
b_{t}^{t}+\frac{1}{1+n} b_{t}^{t-1}=0
$$

for each $t=1,2, \ldots$

Before we look for solutions to this equation, it is useful to learn something about interest rates at which households face binding IRC's. For a member of cohort $v=t$, Lemma 2 says that the middle-age IRC will be binding at $t+1$ if, and only if, $R_{t+1}<\bar{R}_{1}$. The same household will have to contend with a binding constraint in youth if the expected future yield, $R_{t+1}$, is low for a given current yield, $R_{t}$. That event tightens borrowing limits on the young: it boosts their constrained asset demand, which is decreasing in $R_{t+1}$, above the corresponding unconstrained demand, which is increasing in $R_{t+1}$. The technical result (proved in appendix A.2) is

Lemma 3 If Assumption 2 holds, there exists a continuously differentiable, decreasing function $m:\left[0, \bar{R}_{0}\right] \rightarrow \mathcal{R}_{+}$such that:

1. Members of cohort $t$ are debt-constrained at $t+1$ if, and only if, $R_{t+1}<\bar{R}_{1}$.

2. The same group is debt-constrained at $t$ if, and only if, $R_{t+1}<m\left(R_{t}\right)$.

3. The function $m$ satisfies $m\left(\bar{R}_{0}\right)=\bar{R}_{1}$ and has a unique fixed point at $R^{*} \in$ $\left(\bar{R}_{1}, \bar{R}_{0}\right)$.

Continuing with the example at the end of Section 3, suppose again that $\beta=$ $1, u(c)=\log c, n=0, y^{t}=(e, 1, e)$ with $0<e<1$. Constrained asset demands are now

$$
\begin{aligned}
b_{t}^{t} & = \begin{cases}0 & \text { if } R_{t+1} \leq \bar{R}_{1}=e \\
-\left(1-\sqrt{e / R_{t+1}}\right)^{2} / R_{t} & \text { otherwise }\end{cases} \\
b_{t+1}^{t} & = \begin{cases}0 & \text { if } R_{t+1} \leq \bar{R}_{1}=e \\
\frac{1}{2}\left(1+R_{t} b_{t}^{t}-e / R_{t+1}\right) & \text { otherwise }\end{cases}
\end{aligned}
$$


If we compare these with the unconstrained demands of Section 3, we find that debt constraints bind on the middle-aged if $R_{t+1}<e$; they bind on the young if both $R_{t+1} \geq e$ and

$$
e R_{t}<\mu\left(R_{t+1}\right) \equiv 3 \sqrt{\frac{e}{R_{t+1}}}-\left(1+\frac{e}{R_{t+1}}\right)
$$

\section{$5 \quad$ Stationary states without commitment}

This section studies the properties of steady states in our perfect-foresight economy without commitment. The income effects that arise from changes in debt limits may overcome the substitutability of intertemporal consumption dictated by the utility function, permitting three, instead of one, steady states in equilibrium. One steady state is unconstrained and identical to that of the corresponding commitment economy; it carries a large interest rate, large potential gains from trade, and generous debt limits for the young. Constraints are slack in this equilibrium.

Another steady state is completely autarkic with no borrowing or lending in equilibrium, and a loan yield no bigger than the autarkic marginal rate of substitution for middle-age individuals. This equilibrium has poor welfare properties: it imposes zero debt limits on everyone and allows no gains from trade. Autarkic allocations are constrained-suboptimal and can be easily improved by a benevolent central planner that respects the IRC's.

Between autarky and no-rationing lies a constrained state with an intermediate loan yield and binding debt limits. Here the gains from trade are modest, and young consumers desire to borrow more than their rations permit.

In formal language, steady states are time-invariant lists $\left(c_{0}, c_{1}, c_{2}, w, R\right)$ for the lifecycle consumption vectors, the debt load $w$, and the interest rate yield $R$, with the property that all cohorts are either debt-constrained in youth or unconstrained in any stage of life. ${ }^{7}$ At a constant yield $R$, aggregate demand for consumption loans is the sum of the corresponding demands by young and middle-aged households. From Lemma 1.3, Theorem 2 and equation (9), we obtain aggregate asset demands

$$
D_{u}(R)=B(R, R)+\frac{1}{1+n} z[R,-R B(R, R)]
$$

if debt constraints are always slack; and

$$
D_{c}(R)=\frac{f(R)}{R}+\frac{1}{1+n} z[R,-f(R)]
$$

\footnotetext{
${ }^{7}$ Assumption 2 guarantees that middle-age individuals are unconstrained at steady states.
} 
if debt constraints always bind on the young. Stationary solutions to the market clearing condition (26) then satisfy:

$$
\max \left\{D_{u}(R), D_{c}(R)\right\}=0
$$

We already know from Lemma 3, particularly from parts 1 and 2, that debt constraints will bind on the young if the interest rate is small enough. In particular, we directly obtain

Lemma 4 Let $R^{*} \in\left(\bar{R}_{1}, \bar{R}_{0}\right)$ be the unique fixed point of the map $m:\left[0, \bar{R}_{0}\right] \rightarrow$ $\mathcal{R}_{+}$which defines the boundary of the constraint set $\left\{\left(R_{t}, R_{t+1}\right) \in \mathcal{R}_{+}^{2} \mid B\left(R_{t}, R_{t+1}\right) \leq\right.$ $\left.\left.f\left(R_{t+1}\right) / R_{t}\right)\right\}$.

Proof: see appendix A.3.

Using Lemma 3.2, we find that the stationary demand for assets is debt constrained if, and only if, $R<R^{*}$. Figure 3 draws the stationary community asset demand for $\beta=1, u(c)=\log c, n=0, y^{t}=(0.2,1,0.2)$. One noteworthy feature of this graph is the non-monotonicity of demand due to binding constraints that weaken the intertemporal consumption substitutability. Debt constraints are slack for any $R \geq R^{*}$, and community asset demand is monotone in $R$ because all dated consumption goods are gross substitutes at high interest rates. The situation changes when $R<R^{*}$ : binding debt constraints lead to complementarity between youthful and old-age consumption, and to non-monotonicity of the asset demand schedule.

\section{[FIGURE 3 ABOUT HERE]}

To characterize steady states in economies without commitment, it is useful to proceed by comparing the stationary yield, $R_{u}^{*}$, of the commitment equilibrium with the fixed point, $R^{*}$, of the line that separates the constrained set of yields from the unconstrained one. Let $w^{*}$ be the debt load corresponding to $R^{*}$.

Economies with peaky endowment profiles, low rates of time preference and moderate intertemporal elasticities of substitution, like the one in Figure 3, impose a high penalty on defaulting borrowers and will satisfy $R_{u}^{*} \geq R^{*}$. Here, debt limits will be high for any given vector of yields that exceeds $\bar{R}_{1}$. The commitment equilibrium yield $R_{u}^{*}$ will also be a stationary equilibrium in a no-commitment economy with slack debt constraints. However, this equilibrium will no longer be unique: it will coexist with two additional constrained stationary allocations.

One allocation is autarkic and nominally indeterminate: all generations hold zero assets, and the loan yield is any $R \in\left(0, \bar{R}_{1}\right]$, that is, any yield up to the autarkic marginal rate of substitution of the most patient age group. Any yield $R \leq \bar{R}_{1}$ is, by Assumption 2, below the growth factor $1+n$ for this economy. Hence, the autarkic allocation is constrained-suboptimal and it can be improved by a benevolent central 
planner who spreads consumption more evenly over the lifecycle and still respects the IRC's (18) and (19).

Another equilibrium occurs at an intermediate yield $R_{c}^{*} \in\left(\bar{R}_{1}, R^{*}\right)$, where the borrowing limit of the young is reduced by low expected future yields to the point where it falls below the relevant unconstrained demand. This allocation may or may not be constrained optimal. It is optimal if $R_{c}^{*} \geq 1+n$ because the discounted value of the aggregate endowment profile is finite at both the market interest rate charged by creditors, and also at the higher marginal rate of substitution of rationed debtors.

Economies with low default penalties correspond to relatively flat endowment profiles or high intertemporal elasticities of substitution. Here the only possible stationary equilibrium is autarky at an indeterminate yield $R \in\left(0, \bar{R}_{1}\right]$. As we shall see in section 6 , dynamic competitive equilibria generally fail to exist in economies with identical cohorts when assets are in zero net supply.

Stationary equilibria and their welfare properties are summed up in

Theorem 4 Let $R_{u}^{*} \in\left(\bar{R}_{1}, \bar{R}_{0}\right)$ be the unique stationary yield of the commitment economy, and $R^{*} \in\left(\bar{R}_{1}, \bar{R}_{0}\right)$ be the unique fixed point of the constraint set defined in Lemma 4. Then

1. If $R_{u}^{*} \geq R^{*}$, the no-commitment economy has one unconstrained stationary equilibrium at $R_{u}^{*}$, one autarkic constrained equilibrium with identically zero asset holdings at any $R \leq \bar{R}_{1}$, and one constrained non-autarkic equilibrium with nonzero asset holdings at $R_{c}^{*} \in\left(\bar{R}_{1}, R^{*}\right)$.

2. If $R_{u}^{*}<R^{*}$, the no-commitment economy has a unique stationary autarkic equilibrium at $R \leq \bar{R}_{1}$.

3. The autarkic steady state is constrained-suboptimal. Moreover, stationary allocations are constrained-optimal if the aggregate endowment vector has finite value when evaluated at the marginal rate of substitution of unconstrained agents.

Proof: See Appendix A.4. ${ }^{8}$

Continuing with the example of Sections 3 and 4 , consider an economy with $\beta=$ $1, u(c)=\log c, n=0, y^{t}=(e, 1, e)$, with $0<e<1$. Then $R^{*}$ is the solution to the equation

$$
e R=\mu(R) \rightarrow e R^{2}+R-3 \sqrt{e R}+e=0 .
$$

For $e \leq 0.25, R_{u}^{*} \geq R^{*}$ and there are three steady states: (a) the unconstrained steady state $\left(w_{u}^{*}, R_{u}^{*}\right)=((1-e) / 3,1)$; (b) the autarkic steady state $\left(w, \bar{R}_{1}\right)=(0, e)$; (c) the non-autarkic constrained steady state $\left(w_{c}^{*}, R_{c}^{*}\right)$ where

$$
w_{c}^{*}=-f\left(R_{c}^{*}\right)=\left(1-\sqrt{\frac{e}{R_{c}^{*}}}\right)^{2}
$$

\footnotetext{
${ }^{8}$ We thank an anonymous referee for suggesting part 3 of Theorem 4 .
} 
and $R_{c}^{*}$ is the unique solution to

$$
\frac{f(R)}{R}+\frac{1}{2}\left(1+f(R)-\frac{e}{R}\right)=0 \quad \leftrightarrow \quad-R(1+e)+(2+R) \sqrt{e R}-e=0
$$

in the interval $\left(\bar{R}_{1}, R^{*}\right)$. For $0<e<0.25, R_{u}^{*}$ is below $R^{*}$ and the unique stationary solution is the autarkic steady state.

\section{Regimes of dynamic equilibria}

This section studies dynamic equilibria and explores their convergence to the steady states studied in Section 5. The key geometric issue is to understand how the phase diagram in Figure 1 changes in the presence of debt limits. As one may expect, we find that the loss of gross substitutability generates a rich pattern of complex dynamic behavior which is easiest to understand if we start with the commitment economy in Figure 1. That figure says that equilibrium converges to the unconstrained state $\left(w_{u}^{*}, R_{u}^{*}\right)$ from any value of the principal-and-interest, $w_{1}$, owed by the initial middleaged to the initial old, between $-y_{2}$ and the boundary of the region in which $z\left(R_{1}, w_{1}\right) \geq$ $-y_{0}$, that is for any initial debt that the debtor can afford to repay.

Without commitment, the initial values of debt loads that will be repaid necessarily shrink from what they can afford to what they choose to repay. Since the old will always default on all debt and the middle aged will refuse to repay large debts, it is easy to see why unconstrained equilibria will converge to the steady state $\left(w_{u}^{*}, R_{u}^{*}\right)$ only from a relatively small interval of positive initial debt $\left[\bar{w}_{1}, \bar{w}_{2}\right]$, as shown in Figure 4 . Very small initial debt loads in the interval $\left[0, \bar{w}_{1}\right)$ rule out unconstrained equilibria because they induce the middle aged to lend a lot, lowering interest rates and violating the debt constraint on the young.

By the same token, very small initial debt loads in the interval $\left[0, \bar{w}_{c}\right]$ tighten debt constraints and support rationed dynamic equilibria that converge to the constrained steady state $\left(w_{c}^{*}, R_{c}^{*}\right)$. No initial debt load, other than $w_{1}=0$, is consistent with a purely autarkic equilibrium.

In formal language, a sequence $\left(w_{t}, R_{t}\right)_{t=1}^{\infty}$ of debt loads and loan yields is a dynamic equilibrium if $w_{1} \in\left[0, y_{1}\right]$ is given by history, and for each $t,\left(w_{t}, R_{t}\right)$ solves the individual maximization problem (17), satisfies the IRC's (18), (19) and the asset market clearing condition (26). In particular, an equilibrium satisfies IRC's on the middle aged that require non-negative saving

$$
z\left(R_{t}, w_{t}\right) \geq 0 .
$$

In addition, slack debt constraints on the young require non-positive excess demand 
for loans at any yield for which they are slack, i.e.,

$$
J\left(R_{t}, w_{t}\right) \equiv \max \left\{0, \frac{z\left(R_{t}, w_{t}\right)}{1+n}\right\}+B\left(R_{t}, m\left(R_{t}\right)\right) \leq 0 .
$$

The space of feasible equilibrium sequences for the no-commitment economy lies between the lines $z\left(R_{t}, w_{t}\right)=0, J\left(R_{t}, w_{t}\right)=0$ and $w_{t} \geq 0$, as shown in Figures 4 and 5. Allocations below $z\left(R_{t}, w_{t}\right)=0$ have low interest rates and imply negative lending by the middle-aged; allocations to the left of $J\left(R_{t}, w_{t}\right)=0$ have low debt loads for the current middle-aged, which raise lending and lower the equilibrium interest rate, thereby violating the debt constraint on the young. These figures show that the state space is considerably smaller than that of the corresponding commitment economy of Figure 1 because state variables must be consistent with debt constraints.

Competitive equilibria with slack constraints are non-negative solutions $\left(w_{t}, R_{t}\right)$ to the dynamical system described by equations (11) and (12). Geometrically, these sequences lie on the unconstrained equilibrium manifold $\psi_{u}$, defined for the commitment economy by Theorem 2.4, between the lines $z\left(R_{t}, w_{t}\right)=0, J\left(R_{t}, w_{t}\right)=0$ and $w_{t} \geq 0$ of Figures 4 and 5 . In an analogous fashion, equilibria with tight constraints are incentive-compatible solutions to

$$
f\left(R_{t+1}\right)=-R_{t} \frac{z\left(R_{t}, w_{t}\right)}{1+n}
$$

and equation (12). Geometrically, these sequences lie on the constrained manifold $\psi_{c}$, which is studied in detail in Appendix A.6, between the lines $z\left(R_{t}, w_{t}\right)=0, J\left(R_{t}, w_{t}\right)=$ 0 and $w \geq 0$ of Figure 4 and 5 . These sequences converge monotonically to the nonautarkic steady state $\left(w_{c}^{*}, R_{c}^{*}\right)$, which is easily shown to be a saddle. The one exception is when the economy begins with autarky, that is, the initial debt load is $w_{1}=0$. Then the unique equilibrium allocation is the source $\left(w_{t}, R_{t}\right)=(0, R)$, for all $t$, with $R \in\left(0, \bar{R}_{1}\right]$. The reason for the indeterminate autarkic yield is well known from the literature on incomplete markets: the complete absence of trading is consistent with any equilibrium yield less than, or equal to, the marginal rate of substitution of the most patient trader, i.e. of middle-aged individuals.

Consider first economies with $\left(\beta, y_{1} / y_{0}, y_{1} / y_{2}\right)$ large and $\sigma$ small, so that $R_{u}^{*}>R^{*}$. Households value consumption smoothing greatly. Theorem 4 showed that the economy without commitment has three stationary equilibrium allocations

$$
\left(w_{t}, R_{t}\right)=\left\{\left(w_{u}^{*}, R_{u}^{*}\right),\left(w_{c}^{*}, R_{c}^{*}\right),(0, R) \text { for } R \in\left(0, \bar{R}_{1}\right)\right\}, \forall t .
$$

Figure 4 shows the dynamic equilibria for this economy. Converging to the unconstrained steady state $\left(w_{u}^{*}, R_{u}^{*}\right)$ are sequences of dynamic equilibria with slack constraints that start from a historically given value $w_{1}$ and lie on the incentive-compatible portion of the commitment equilibrium manifold $\psi_{u}$. The following result is proved in Appendix A.5: 
Theorem 5 Suppose $R_{u}^{*}>R^{*}$. Then there exist critical values $\bar{w}_{1} \in\left[0, w_{u}^{*}\right]$ and $\bar{w}_{2} \in\left[w_{u}^{*}, y_{1}\right]$ for the debt load such that:

1. At most one unconstrained equilibrium sequence exists for any initial value, $w_{1}$, of the debt load.

2. An unconstrained equilibrium sequence exists if, and only if, $w_{1} \in\left[\bar{w}_{1}, \bar{w}_{2}\right]$.

3. The unconstrained equilibrium manifold spans the critical values $w^{*}$ and $R^{*}$.

Figure 4 shows that the values $\left(\bar{w}_{1}, \bar{w}_{2}\right)$ are the intersections of the manifold $\psi_{u}$ with the incentive-compatibility lines $J=0$ and $z=0$. Hence, the commitment equilibrium manifold $\psi_{u}$ of the no-commitment economy is defined only for debt loads $w_{t} \in\left[\bar{w}_{1}, \bar{w}_{2}\right], \forall t$. Intuitively, only positive but moderate debt loads satisfy the IRC's of young and middle-age individuals. For any initial condition $w_{1} \in\left[\bar{w}_{1}, \bar{w}_{2}\right]$, there is a unique unconstrained equilibrium sequence that approaches non-monotonically the unconstrained steady state.

\section{[FIGURE 4 ABOUT HERE]}

The second stationary allocation is the constrained non-autarkic equilibrium $\left(w_{c}^{*}, R_{c}^{*}\right)$. This steady state is a saddle and convergence toward it is monotonic. In comparing the constrained non-autarkic steady state with the unconstrained one, we find that: (a) the debt load and the interest rate are lower at the constrained non-autarkic steady state, $w_{c}^{*}<w_{u}^{*}, R_{c}^{*}<R_{u}^{*}$; and (b) there is less borrowing and lending at the constrained non-autarkic steady state, $f\left(R_{c}^{*}\right) / R_{c}^{*}>B\left(R_{u}^{*}, R_{u}^{*}\right)$.

Theorem 6 Suppose $R_{u}^{*}>R^{*}$. Then there is a critical value, $\bar{w}_{c} \in\left[\bar{w}_{1}, w_{u}^{*}\right)$, for the debt load such that:

1. If $w_{1}=0$, autarky is an equilibrium allocation.

2. If $w_{1} \in\left(0, \bar{w}_{c}\right]$, there is a unique non-autarkic equilibrium sequence with tight debt constraints that converges monotonically to $\left(w_{c}^{*}, R_{c}^{*}\right)$.

3. If $w_{1}>\bar{w}_{c}$, there is no equilibrium sequence with tight debt constraints.

4. The constrained equilibrium manifold $\psi_{c}$ spans the critical values $w^{*}$ and $R^{*}$.

Proof: See Appendix A.6.

Approaching the constrained non-autarkic steady state are sequences of dynamic equilibria with tight debt constraints that start from a historically given value $w_{1}$ and lie on the incentive-compatible portion of the constrained manifold $\psi_{c}$. This is defined for debt loads $w_{t} \in\left(0, \bar{w}_{c}\right]$, where $\bar{w}_{c}$ is shown to be the intersection between 
the constrained manifold $\psi_{c}$ and the incentive-compatible line for the young $J=0$ in Figure 4. Large values of the initial debt load violate the IRC for the young and are outside the domain of the constrained equilibrium manifold.

The third stationary allocation in the economy is the constrained autarkic equilibrium $(0, R)$, for $R \in\left(0, \bar{R}_{1}\right]$, characterized by zero borrowing and lending. When the economy begins with autarky, that is, initial debt load is $w_{1}=0$, then the unique equilibrium allocation is the source $\left(w_{t}, R_{t}\right)=(0, R)$, for all $t$, with $R \in\left(0, \bar{R}_{1}\right]$. The autarkic steady state is unstable, and any shock leading to positive debt loads makes the economy move away from it. In welfare terms, the autarkic stationary allocation is Pareto-dominated by the constrained non-autarkic stationary allocation. This is hardly a surprise since autarky is associated with a peaky consumption profile in this economy.

Figure 4 illustrates the manifold $\psi_{c}$ which overlaps with the unconstrained manifold $\psi_{u}$ for $w_{t} \in\left[\bar{w}_{1}, \bar{w}_{c}\right]$. Equilibrium is indeterminate whenever the debt load is in this interval. More precisely, debt loads in this interval belong to both the constrained and the unconstrained equilibrium sequences.

Multiple equilibria will thus appear for a wide range of initial conditions. First, if $w_{1}$ lies in the overlapping region $\left[\bar{w}_{1}, \bar{w}_{c}\right]$; second, if the initial value $w_{1}$ is sufficiently larger than $w_{u}^{*}$ so that the unconstrained manifold will lead its successor, $w_{2}$, into the overlap region; third, if either the constrained stationary allocations are spanned by the unconstrained manifold, or the unconstrained stationary allocation is spanned by the constrained manifold, or both.

We do not know if the constrained steady state $\left(w_{c}^{*}, R_{c}^{*}\right)$ or the unconstrained one $\left(w_{u}^{*}, R_{u}^{*}\right)$ are generally spanned by the equilibrium manifold of the other steady state. If neither state is spanned, then equilibrium will be unique for $w_{1} \in\left[0, \bar{w}_{1}\right]$ or for $w_{1}$ sufficiently close to $w_{u}^{*}$ : in the former case, debt constraints bind for all $t$, and the equilibrium sequence converges to the constrained state; in the latter case, debt constraints are slack for all $t$, and the equilibrium sequence converges to the unconstrained state.

If the constrained non-autarkic steady state is spanned by the unconstrained manifold, then the equilibrium is not unique for $w_{1} \in\left(0, \bar{w}_{1}\right]$. The economy can switch from $\psi_{c}$ to $\psi_{u}$ once it enters the overlap region. Along the same lines, if the unconstrained steady state is spanned by the constrained manifold, the equilibrium is not unique for any $w_{1} \in\left[\bar{w}_{c}, \bar{w}_{2}\right]$.

As long as the overlap region between the two manifolds is not empty, indeterminacy of perfect-foresight equilibria may persist for one or more periods. We call this phenomenon sequential indeterminacy and give an example of it in the next paragraph. Equilibria with binding and slack constraints may coexist for several time periods, and either one of the steady states $\left(w_{c}^{*}, R_{c}^{*}\right),\left(w_{u}^{*}, R_{u}^{*}\right)$ can be reached from the initial debt load $w_{1}$. When both equilibrium manifolds span one or more stationary allocations, then the economy can move from one equilibrium manifold to the other even after a 
stationary allocation has been reached. These equilibria have countably infinite degrees of freedom and display an extreme form of recurrent indeterminacy. It is worth noting that Theorems 5 and 6 do not require any form of dynamic inefficiency in the underlying full-commitment economy. Hence, complex dynamic behavior under endogenous debt constraints has little to do with dynamic efficiency, as the following example demonstrates.

Continuing with the example of the previous sections, consider the economy with $\beta=1, u(c)=\log c, n=0, y^{t}=(e, 1, e)$ with $e=8 / 45<1 / 4$. For this economy, the commitment equilibrium at $R_{u}^{*}=1$ is dynamically efficient. Without commitment, we have $z(R, w)=(1-w) / 2+f(R) / R, f(R)=-(1-\sqrt{e / R})^{2}$, and the manifold $\psi_{c}$ is defined by $w=-f(R)$, that is, by the joint solution of equations (12) and (32). Then we easily check from figure 4 that $\psi_{c}$ starts at the point $(w, R)=\left(0, \bar{R}_{1}\right)=(0, e)=$ $(0,8 / 45)$ and ends at $(w, R)=\left(\bar{w}_{c}, \bar{R}_{c}\right)=(4 / 9,72 / 45)$. To see this, we recall that $\left(\bar{w}_{c}, \bar{R}_{c}\right)$ is the common solution to equations $J(R, w)=z(R, w)+f(R) / R=0$ and $w=-f(R)$. We conclude that the constrained manifold for this economy spans the unconstrained steady state $\left(w_{u}^{*}, R_{u}^{*}\right)=((1-e) / 3,1)=(37 / 135,1)$.

Consider now the case where $\left(\beta, y_{1} / y_{0}, y_{1} / y_{2}\right)$ are small and $\sigma$ is large, so that $R_{u}^{*}<R^{*}$. These households have a high intertemporal elasticity of substitution and place little value on consumption smoothing. At the same time, the endowment profile is relatively flat and future punishments are discounted heavily. In this economy, individuals have a strong incentive to default and face very tight debt limits.

From Theorem 4, we know that this economy has a unique stationary autarkic allocation $(0, R)$ for any $R \in\left(0, \bar{R}_{1}\right], \forall t$; we also know that there are no equilibrium gains from trade at $\left(w_{u}^{*}, R_{u}^{*}\right)$, which fails to be an incentive-compatible allocation. Walrasian perfect-foresight equilibrium does not exist in this class of economies without commitment: any initial condition $w_{1} \in\left(0, \bar{w}_{2}\right]$ leads to equilibrium sequences that result in default by middle-aged individuals, thereby violating our definition of equilibrium.

The geometric reason why equilibrium does not exist is shown in Figure 5, which draws the manifolds $\psi_{u}$ and $\psi_{c}$ for this economy. The equilibrium manifold has a "hole" in the interval $\left(\bar{w}_{c}, \bar{w}_{1}\right)$ which contains the unconstrained steady state $\left(w_{u}^{*}, R_{u}^{*}\right)$. For this reason, the "hole" will attract all sequences $\left(w_{t}, R_{t}\right)$ that start on either $\psi_{u}$ or $\psi_{c}$ anywhere in the domain $\left(0, \bar{w}_{2}\right]$. Therefore, no equilibrium exists for any initial $w_{1}$, other than $w_{1}=0$. The following result follows immediately.

Theorem 7 Suppose $R_{u}^{*}<R^{*}$. Then equilibrium is autarkic if $w_{1}=0$, and no equilibrium exists if $w_{1} \neq 0$.

\section{[FIGURE 5 ABOUT HERE]}

Figure 6 sums up how existence results from Theorems 5, 6 and 7 depend on the initial debt load $w_{1}$, preferences and the endowment profile. Equilibrium does not exist 
for $R_{u}^{*}<R^{*}$ or for extreme values of the initial debt load outside the interval $\left[0, \bar{w}_{2}\right]$. Moderately low values of $w_{1} \in\left(0, \bar{w}_{1}\right)$ lead to initially constrained equilibrium, while $w_{1} \in\left[\bar{w}_{c}, \bar{w}_{2}\right]$ means that equilibria will start with slack constraints. Both situations are possible when $w_{1} \in\left(\bar{w}_{1}, \bar{w}_{c}\right)$.

\section{[FIGURE 6 ABOUT HERE]}

\section{Comparison with exogenous debt constraints}

This section explores the conjecture that the complex dynamical equilibria found in our model are neither the inherent property of lifecycle economies with many trading periods, nor the outcome of dynamic inefficiency. We claim instead that indeterminacy and complex dynamics stem from the large income effects associated with the impact of yield changes on endogenous debt constraints in any environment where defaulters are excluded from intertemporal market activity for finitely many, and typically few, trading periods. Large income effects of this type may occur not only in our setting, but also in those of Bewley [10] and Kehoe and Levine [25] if sanctions on defaulters lasted exactly one period instead of none and infinitely many, respectively.

To develop this argument further, we examine two variations of the model studied earlier. The first variant replaces our endogenous debt constraints with liquidity constraints à la Jappelli and Pagano [21]. The second variant features a dynamically inefficient economy where loans are prohibited and the only store of value is a fixed stock of fiat money per person. We already presented in Section 6 a parametric example showing how sequential indeterminacy may occur in economies without commitment even if the corresponding commitment economy is dynamically efficient.

\subsection{Liquidity Constraints}

Following Jappelli and Pagano [21], we assume that default is punished by garnishing a fixed fraction $\phi \in[0,1]$ of the defaulter's current and future endowment. In other words, we relax the assumption that private endowments cannot be seized following default and express this restriction as:

$$
\begin{gathered}
c_{t}^{t}=y_{0}-b_{t}^{t} \leq y_{0}+\frac{\phi}{R_{t}}\left(y_{1}+\frac{y_{2}}{R_{t+1}}\right) \\
c_{t+1}^{t}=y_{1}+R_{t} b_{t}^{t}-b_{t+1}^{t} \leq y_{1}+\frac{\phi y_{2}}{R_{t+1}} .
\end{gathered}
$$

Kehoe and Levine [25] examine the implications of these constraints in an economy with infinitely-lived agents facing idiosyncratic income risk, perpetual exclusion after 
default, and $\phi=0$. They find that liquidity constraints prolong the impact of shocks on individual consumption. We, on the other hand, want to know if liquidity constraints contribute to indeterminacy.

The restrictions above imply debt constraints of the form

$$
\begin{gathered}
b_{t}^{t} \geq-\frac{\phi}{R_{t}}\left(y_{1}+\frac{y_{2}}{R_{t+1}}\right) \\
b_{t+1}^{t} \geq-w_{t+1}-\frac{\phi y_{2}}{R_{t+1}} .
\end{gathered}
$$

Each of these is increasing in $\left(R_{t}, R_{t+1}\right)$. When the constraints do not bind, asset demands are the unconstrained demands of Section 2. The analysis can then proceed as in our model. Specifically, asset demands are given by (24) and (25), with (34) replacing $f\left(R_{t+1}\right) / R_{t}$ and (35) replacing zero. Community asset demand at $t$ is

$$
B_{\phi}\left(R_{t-1}, R_{t}, R_{t+1}\right)=b_{t}^{t}+\frac{b_{t}^{t-1}}{1+n},
$$

which is monotone increasing in its arguments. This implies that: (a) there is at most one steady state at which individuals are either unconstrained or constrained; and (b) consumption goods at all dates are gross substitutes.

If the fraction $\phi$ is large enough, borrowing may be unconstrained in the sense that neither the debt constraint (34) nor (35) is binding. Unconstrained equilibria exist and converge non-monotonically to the steady state $\left(w_{u}^{*}, R_{u}^{*}\right)$ studied in Section 3.

If the fraction $\phi$ is not large enough, borrowing may be constrained. Let's consider the case where young agents are constrained while middle-aged ones are not, i.e. (34) is binding while (35) is not. In our notation, equilibrium sequences satisfy

$$
D_{\phi}\left(R_{t}, R_{t+1}\right) \equiv-\frac{\phi}{R_{t}}\left(y_{1}+\frac{y_{2}}{R_{t+1}}\right)+\frac{1}{1+n} z\left(R_{t}, \phi\left(y_{1}+\frac{y_{2}}{R_{t}}\right)\right)=0,
$$

which is a first-order difference equation. Equation (37) has a unique solution $R_{c}^{*}<R_{u}^{*}$. Inverting $D_{\phi}=0$, we obtain $R_{t+1}=\gamma\left(R_{t}\right)$, where $\gamma$ is a decreasing function for all $R_{t}$ above some critical value $\tilde{R}$. It is easy to show that the unique constrained steady state is a source. Hence, for $\phi$ small, the unique constrained equilibrium $R_{c}^{*}<R_{u}^{*}$ is consistent only with an initial debt load $w_{1}=\phi\left(y_{1}+y_{2} / R_{c}^{*}\right)$; all other initial debt loads are either inconsistent with equilibrium or lead to equilibrium sequences for which the constraint is initially slack for $t \leq T-1$ and tight for all $t \geq T$.

Consider again the economy with $\beta=1, u(c)=\log c, n=0, y^{t}=(e, 1, e)$ with $0<e<1$, and debt constraints as in (34) and (35). If

$$
\frac{1-e}{3(1+e)}<\phi<1
$$


then asset demands are unconstrained and the economy converges to the unique unconstrained steady state calculated at the end of Section 3. Otherwise, the constraint on the young is binding. For low values of $\phi$, there is a unique steady state $0<R_{c}^{*}<1=R_{u}^{*}$, which is also a source.

These findings suggest that exogenous liquidity constraints do not support multiple equilibria, do not contribute to indeterminacy and do not generate the complex dynamic behavior supported by endogenous debt constraints in lifecycle environments.

\subsection{Fiat Money}

Here we tackle the question of whether complex equilibria are possible in a version of our model in which fiat money is the only store of value. By complex equilibria we mean the sequential indeterminacy of Theorems 5 and 6 , which rests crucially on the existence of multiple steady states, rather than the initial-conditions indeterminacy usually found in dynamically inefficient lifecycle economies.

The simplest environment is an OLG economy where agents are unable to borrow, namely, $\phi=0$ in terms of the liquidity constraints of the previous section, but can exchange fiat money for consumption goods. We look at the case of a constant amount of fiat money $\bar{M}$ initially held by the transitional middle-aged and old generations. Individual budget constraints are the same as in (6) to (8) with

$$
b_{t}^{t}=\frac{M_{t}^{t}}{P_{t}}, \quad b_{t+1}^{t}=\frac{M_{t+1}^{t}}{P_{t+1}}, \quad R_{t}=\frac{P_{t}}{P_{t+1}}, \quad M_{t}^{t} \geq 0, \quad M_{t+1}^{t} \geq 0,
$$

where $M_{t}^{t}$ is money demand by the young at $t, M_{t+1}^{t}$ is money demand by the same individual when middle-aged, $P_{t}$ is the price level at $t$ and $R_{t}$ is the real yield on money balances. If $\bar{M}$ is the stock of fiat money in the economy with $\beta=1, u(c)=\log c, n=$ $0, y^{t}=(e, 1, e)$ and $0<e<1$, then equilibria satisfy individual asset demands

$$
\left(b_{t}^{t}, b_{t+1}^{t}\right)=\left(0, \frac{1}{2}\left(1-\frac{e}{R_{t+1}}\right)\right)
$$

plus the market clearing condition

$$
b_{t}^{t-1}=\frac{\bar{M}}{P_{t}} .
$$

This condition implies $b_{t+1}^{t}=R_{t} b_{t}^{t-1}$ or, equivalently,

$$
1-\frac{e}{R_{t+1}}=R_{t}-e .
$$

Equation (38) admits two stationary solutions: an unstable, dynamically efficient steady state $R^{*}=1$ with valued fiat money at $P^{*}=2 \bar{M} /(1-e)$, and a stable, 
dynamically inefficient steady state $R=e<1$ with worthless fiat money at $P=+\infty$. In addition to these stationary states, there will also exist monetary equilibria starting at $P_{1}>P^{*}$ and converging to the autarkic state; these display the initial-conditions indeterminacy typical of dynamically inefficient OLG economies.

We conclude that liquidity constraints with fiat money are inconsistent with complex equilibrium behavior, at least in environments where all goods are normal and gross substitutes. There are two Pareto-rankable steady states, but no sequential indeterminacy.

An environment in which the government prints currency at a constant rate and pays lump-sum subsidies has the same qualitative features as the model with fiat money analyzed above. Here money supply grows over time and there is a stationary equilibrium where nominal money supply and the price level change at a common rate, and real money holding is constant for each generation. Autarky is again a stationary equilibrium and the usual initial-conditions indeterminacy is also present.

\section{Related Literature}

Earlier theories of intertemporal allocation rationalize the evidence against consumption smoothing by stressing the importance of unobservable shocks in informationally constrained environments. ${ }^{9}$ Attanasio and Davis [6], on the other hand, study consumption and wage movements among birth cohorts and education groups, finding evidence of a remarkable failure of consumption insurance in response to relative wage movements across education groups, and across birth cohorts within education groups. Since wages are public information, models of incomplete information cannot rationalize these findings; instead, they provide support for environments like ours with limited enforceability of contracts.

Storesletten, Telmer and Yaron [33] consider a life-cycle model with commitment, aggregate risk and highly persistent idiosyncratic shocks to labor income. Because the idiosyncratic shocks are nearly permanent, risk sharing is imperfect. Increasing income inequality with age goes together with increasing consumption inequality in this setting, just as it does in U.S. data. In this model, middle-age individuals want to save for their retirement whereas young individuals want to save as a precaution against labor market shocks that are hard to insure against. As a result, young and middle-age agents are net savers while old agents are net dissavers.

Our setting provides a complementary rationale to Storesletten et al. for the lack of consumption smoothing. Our model has no risk, and the lack of consumption smoothing over the lifecycle is entirely due to limited enforceability of loan contracts. If we

\footnotetext{
${ }^{9}$ See Atkeson and Lucas [5] and Phelan and Townsend [31] for efficient allocations with hidden effort, Cole and Kocherlakota [14] for efficient allocation with hidden storage.
} 
added a highly persistent idiosyncratic risk, then a precautionary motive for saving would arise to reduce consumption in youth even below the debt limit we derive in Section 4.

To our knowledge, this paper is the first to study an environment with finitely lived agents who face finite exclusion from the intertemporal market after default. It is important to highlight how differences in the length of the exclusion period affect the properties of dynamic equilibria.

Kehoe and Levine [24] examine debt limits resulting from participation constraints in an economy with infinitely lived households. In their setting, default triggers perpetual exclusion from intertemporal trade while same-date exchanges are still permitted. The size of this penalty implies, under certain technical assumptions, the existence of a second-best (constrained efficient) competitive equilibrium with linear prices. Kocherlakota [28] analyzes efficient allocations in a setting with two infinitely lived agents, participation constraints and complete information. Efficient allocations may result in full risk sharing (as the discount factor tends to one), in limited risk sharing or no risk sharing at all, namely in autarky. Alvarez and Jermann [3] show how to model participation constraints as portfolio constraints and generate limited risk sharing in a setting with otherwise complete markets. They also characterize the conditions (high discount rates, low risk aversion, low variance and high persistence of the idiosyncratic shocks) under which autarky is the only feasible allocation.

Our model shares some of the characteristics of infinitely lived agent models; for example, autarky can always be decentralized as a steady state. If Assumption 2 fails, autarky is the unique competitive equilibrium, and it may be constrained efficient. If Assumption 2 holds, then our model, unlike infinite-life models, has the potential for nonexistence of dynamic equilibria when autarky is the only feasible stationary allocation. If the parametric environment supports borrowing and lending, then complex dynamic behavior is likely, and so are multiple equilibria and the excess sensitivity of consumption and of interest rates to small and temporary perturbations in endowments. These features stem from the complementarity of intertemporal consumption that limited enforceability generates in our setting with finite life and finite exclusion.

We suspect that some of the features of our lifecycle setting may be shared by a setting with infinitely lived households in which default is punished with temporary and relatively short exclusion from intertemporal trade. Bewley [10], Woodford [34] and Aiyagari [1] study economies with infinitely-lived agents and stringent exogenous debt constraints and find that consumption smoothing must necessarily rely on buffer stocks of collateral securities, including unproductive assets like inferior real estate, public debt or fiat money. These are outcomes we typically associate with dynamically inefficient overlapping generations, not with infinitely-lived households economies. Chatterjee et al. [13] study an economy with uncollaterilized debt, no commitment to repay, limited exclusion from borrowing after default and shocks to preferences. They 
focus on the steady state; in equilibrium, individuals with low assets and high present marginal utility of consumption default on their loans. Tighter limits on bankruptcy filing, which imply a stronger commitment to repay, will increase borrowing and welfare.

\section{Conclusions and Extensions}

We have studied dynamic competitive equilibria under perfect foresight in a deterministic, pure-exchange economy with finitely lived individuals who cannot commit to repay their loans. For hump-shaped income patterns over the lifecycle, individuals face binding debt limits when young, consumption tracks income early in life, and youth and old-age consumption become complements. Despite the simplicity of the environment (homogeneous households, three-period lifecycle, one store of value in zero net supply), equilibria turn out to be complex. If consumption smoothing is highly valued, there are multiple steady states, persistent indeterminacy and regime switching.

The key innovation of our paper, and the foundation for complex dynamic behavior, lies in the intertemporal complementarity of consumption for debt-constrained households. Complementarity means that an anticipated rise in future interest rates may substantially boost current consumption of constrained households. Indeterminacy, and the potential for excess sensitivity, thus occurs for utility functions that allow consumption to be highly substitutable over time for lenders. We also note that standard forms of exogenous debt limits, like the liquidity constraints used in Jappelli and Pagano [21], are not consistent with complex dynamic behavior because they amplify the substitution effect of interest-rate changes.

We conclude with a few remarks on the robustness of our findings. Within-cohort heterogeneity will not affect results significantly. For instance, if endowments are sufficiently dispersed, then at each equilibrium some households will be constrained and others will be unconstrained. We would still expect several equilibria to exist when the intertemporal elasticity of substitution is low and the endowment profile is peaky; the fraction of constrained households will be different for each equilibrium sequence. We also believe that the mechanisms described here are relevant for economies with production and a richer array of assets.

Lifecycles longer than $L=3$ raise the issue of the length of the exclusion period. We suspect that a short but positive exclusion period will preserve most of the features of our results. From Kehoe and Levine [24], we hazard the guess that longer-lasting punishments will increase the likelihood of both existence and second-best efficiency for competitive equilibria.

Introducing uncertainty will permit trading in securities if individual characteristics are public information and allow bankruptcy as equilibrium under private information. Adding collateral goods, as in Kiyotaki and Moore [27], to our model will dilute the 
impact of IRC's, which will then apply only to non-collateral borrowing. Since collateral goods raise the punishment for default, a reasonable guess in this case is that competitive equilibrium will exist for a larger set of partially collateralized economies.

Finally, debt constraints are likely to have considerable implications for asset prices in economies with limited collateral and a short exclusion period after default. Significant asset price implications are likely because debt constraints limit the potential for arbitrage between non-collateral assets (claims on labor income) and collateral ones (public debt, claims on capital and capital income). We expect that the implied bounds on arbitrage will influence household portfolios by diverting too much wealth away from relatively risky or poorly collateralized assets into buffer stocks of less risky or fully collateralized securities. The outcome may well be what is predicted in Constantinides et al. [15]: an excessive premium on risky assets, combined with anemic yields on collateralized safe securities. 


\section{A Appendix}

\section{A.1 Proof of Lemma 2}

We rely on figure 2, and the definition of the constraint youthful demand for assets. Formally, $B_{y}^{c}\left(R_{t}, R_{t+1}\right)=f\left(R_{t+1}\right) / R_{t}$ solves an equation that expresses indifference between solvency and default, that is,

$$
u\left(y_{1}\right)+\beta u\left(y_{2}\right)=\max _{z \geq 0}\left\{u\left[y_{1}+f\left(R_{t+1}\right)-z\right]+\beta u\left(y_{2}+R_{t+1} z\right)\right\} .
$$

Part 1 follows directly from the fact that the function $u$ is twice continuously differentiable. The monotonicity properties of $B^{c}$, and Part 3 , are direct consequences of equation (A.1) and the envelope theorem. Figure 2 implies that $y_{1}+f\left(R_{t+1}\right)$ tends to a small positive number, $y_{1}-\bar{y}_{1}$, as $R_{t+1} \rightarrow \infty$; this proves Part 4 and completes the proof.

\section{A.2 Proof of Lemma 3}

Part 1 follows directly from figure 2. To prove the remaining statement, we know from equation (24) that members of cohort $t$ are constrained in youth if, and only if

$$
f\left(R_{t+1}\right)>R_{t} B\left(R_{t}, R_{t+1}\right) .
$$

The left-hand side of (A.2) is continuously differentiable and decreasing for all $R_{t+1}>$ $\bar{R}_{1}$; it vanishes at $R_{t+1}=\bar{R}_{1}$. The right-hand side is also continuously differentiable and decreasing for all $\left(R_{t}, R_{t+1}\right) \in \mathcal{R}_{+}^{2}$. Furthermore,

$$
B\left(\bar{R}_{0}, \bar{R}_{1}\right)=0>B\left(\bar{R}_{1}, \bar{R}_{0}\right)
$$

by Assumption 2. By the implicit function theorem, the equation

$$
f[m(R)]=R B(R, m(R))
$$

is uniquely solved by a continuously differentiable, decreasing function $m:\left[0, \bar{R}_{0}\right] \rightarrow$ $\mathcal{R}_{+}$such that $m\left(\bar{R}_{0}\right)=\bar{R}_{1}<\bar{R}_{0}$ and $m\left(\bar{R}_{1}\right)>\bar{R}_{1}$. Therefore $m$ has a unique fixed point $R^{*} \in\left(\bar{R}_{1}, \bar{R}_{0}\right)$.

\section{A.3 Proof of Lemma 4}

First we define $v(y, R)$ to be the indirect utility function of any middle-age person in cohort $v=t$ facing lifecycle income $y$ over the last two periods of life, and yield $R>0$. The utility gains from intertemporal trades for this person are then $v\left(y_{1}-\right.$ $\left.w_{t+1}+y_{2} / R_{t+1}, R_{t+1}\right)-v\left(y_{1}-\bar{w}_{t+1}+y_{2} / R_{t+1}, R_{t+1}\right)$ where $\bar{w}_{t+1}=-f\left(R_{t+1}\right)$. 


\section{A.4 Proof of Theorem 4}

This proof relies on Lemma 4, and relates to Figure 3. From equation (29) we recall that steady-state yields are zeros of the continuous aggregate asset demand schedule

$$
D(R)= \begin{cases}D_{u}(R) \equiv B(R, R)+\frac{1}{1+n} z[R,-R B(R, R)] & \text { if } R \geq R^{*} \\ D_{c}(R) \equiv \frac{f(R)}{R}+\frac{1}{1+n} z[R,-f(R)] & \text { if } R \in\left(\bar{R}_{1}, R^{*}\right) \\ 0 & \text { if } R<\bar{R}_{1}\end{cases}
$$

The top line describes unconstrained asset demand and, hence, $D\left(R_{u}^{*}\right)=0$ and $\lim _{R \rightarrow \infty}$ $D(R)>0$. In addition, $R^{*}>\bar{R}_{1}$ by Lemma $3 ; f(R)$ vanishes at $R=\bar{R}_{1}$ with a zero derivative by Lemma 2 ; and $z\left(\bar{R}_{1}, 0\right)=0$ by the definition of the yield $\bar{R}_{1}$ in Assumption 2 and the function $z$ in Lemma 1 . Therefore, at $\bar{R}_{1}$, the aggregate demand $D(R)$ vanishes with a positive derivative.

The gross substitutes assumption for unconstrained asset demand means that $D\left(R^{*}\right)$ $<0$ if, and only if, $R^{*}<R_{u}^{*}$. In that event, the continuity of asset demand dictates that $D(R)<0$ for all $R$ below $R^{*}$ and close to it, and $D(R)>0$ for all $R$ above $\bar{R}_{1}$ and close to it. The existence of at least one stationary yield $R_{c}^{*} \in\left(\bar{R}_{1}, R^{*}\right)$ follows immediately from the maintained assumption $R^{*}<R_{u}^{*}$. This proves Part 1 of the theorem.

The non-autarkic constrained steady state is unique if the middle-age saving function $z(R, w)$ satisfies the additional technical condition

$$
\frac{R}{z} \frac{\partial z}{\partial R}+\frac{\partial z}{\partial w}<n, \quad \forall(R, w) \in \mathcal{R}_{+}^{2}
$$

which means that the income effect of an interest rate change on constrained borrowers cannot be too large, and the asset demand schedule $D_{c}(R)$ cannot bend backward "too rapidly". Inequality (A.4) and Lemma 2.3 directly imply that the constrained excess demand function $D_{c}(R)$ is increasing at any constrained steady state $\tilde{R} \in\left[\bar{R}_{1}, R^{*}\right]$. Specifically, for $\tilde{w}=-f(\tilde{R})$, we have

$$
\begin{aligned}
D_{c}^{\prime}(\tilde{R}) & =-\frac{z(\tilde{R}, \tilde{w})}{\tilde{R}^{2}}+\frac{1}{1+n}\left[\frac{\partial}{\partial R} z(\tilde{R}, \tilde{w})-f^{\prime}(\tilde{R}) \frac{\partial}{\partial w} z(\tilde{R}, \tilde{w})\right] \\
& =-\frac{z(\tilde{R}, \tilde{w})}{(1+n) \tilde{R}}\left[-n+\frac{\tilde{R}}{z} \frac{\partial z}{\partial R}+\frac{\partial z}{\partial w}\right]<0
\end{aligned}
$$

whenever $\tilde{R} \geq \bar{R}_{1}, \tilde{w} \geq 0$ and $D_{c}(\tilde{R})=f(\tilde{R}) / \tilde{R}+z(\tilde{R}, \tilde{w}) /(1+n)=0$.

Part 2 corresponds to Figure 3 . We note first $R_{u}^{*}$ is no longer a zero of the excess demand function; also, any $R \leq \bar{R}_{1}$ supports an autarkic stationary allocation. Non-autarkic stationary equilibria may exist in principle, but the argument in the previous paragraph will rule them out if the asset demand does not bend backward "too 
sharply". In particular, Figure 3 implies that non-autarkic steady states exist in pairs, and one member of each pair violates inequality (A.3).

For Part 3 we define second-best efficiency (or constrained optimality) by the allocations achievable by a central planner who maximizes social welfare subject to the resource constraint

$$
c_{t}^{t}+\frac{c_{t}^{t-1}}{1+n}+\frac{c_{t}^{t-2}}{(1+n)^{2}} \leq y_{0}+\frac{y_{1}}{1+n}+\frac{y_{2}}{(1+n)^{2}}
$$

and the IRCs in (18) and (19). IRCs in a planning problem mean that individuals can opt out of a planned allocation at any point in their lifecycle, choosing autarky instead.

A stationary allocation $\left(c_{0}, c_{1}, c_{2}\right) \in \mathcal{R}_{+}^{3}$ is a constrained optimum with equal treatment if it maximizes the social welfare function

$$
W=\alpha_{0} u\left(c_{0}\right)+\alpha_{1} u\left(c_{1}\right)+\alpha_{2} u\left(c_{2}\right)
$$

for a given positive vector $\left(\alpha_{0}, \alpha_{1}, \alpha_{2}\right)$ which represents the weights $\left(\lambda_{0}, \lambda_{1}, \lambda_{2}\right) \geq 0$ of the cohorts $v=-1, v=0$ and $v>0$, respectively, subject to the constraint (A.5) and the participation constraints (18) and (19). Specifically, the social welfare parameters $\left(\alpha_{0}, \alpha_{1}, \alpha_{2}\right)$ satisfy

$$
\alpha_{0}=\lambda_{2}, \quad \alpha_{1}=\beta \lambda_{2}+\lambda_{1}, \quad \alpha_{2}=\beta^{2} \lambda_{2}+\beta \lambda_{1}+\lambda_{0} .
$$

The first-order conditions for this problem yield

$$
\frac{u^{\prime}\left(c_{0}\right)}{\beta u^{\prime}\left(c_{1}\right)} \geq 1+n
$$

with strict inequality if the young are rationed at the allocation $\left(c_{0}, c_{1}, c_{2}\right)$; and

$$
\frac{u^{\prime}\left(c_{1}\right)}{\beta u^{\prime}\left(c_{2}\right)} \geq 1+n
$$

with strict inequality if the middle-age are rationed. Assumption 2 says that (A.7) and (A.8) are violated at the autarkic steady state which, therefore, is not a constrained equal-treatment optimum.

Suppose now that a stationary allocation $\left(c_{0}^{*}, c_{1}^{*}, c_{2}^{*}\right)$ satisfies both (A.7) and (A.8) with strict inequality which means that unconstrained agents attach finite value to the infinitely long aggregate endowment vector. Then one can easily show that allocation to be a constrained equal-treatment optimum by finding multipliers $\left(\pi_{1}^{*}, \pi_{2}^{*}\right) \geq 0$ for the participation constraints such that the vector $\left(c_{0}^{*}, c_{1}^{*}, c_{2}^{*}, \pi_{1}^{*}, \pi_{2}^{*}\right)$ satisfies exactly the first-order conditions for the planner's problem described above. 


\section{A.5 Proof of Theorem 5}

This result characterizes solutions $\left(w_{t}, R_{t}\right)_{t=1}^{\infty}$ to equations (12) and (32) which conform to the constraints (30) and (31). Figure 4 and 5 show that these solutions are defined for $(R, w) \in\left[\bar{R}_{1}, \infty\right) \times\left[0, \bar{y}_{1}\right]$ in the state space bounded by the equalities $J(R, w)=0$ and $z(R, w)=0$. Both $J$ and $z$ are increasing in $\mathrm{R}$ and decreasing in $w$; furthermore, $z\left(\bar{R}_{1}, 0\right)=0$; $\lim _{R \rightarrow \infty} z\left(R, \bar{y}_{1}\right)=0$; and $J \geq f[m(R)] / R$ for all $R \geq \bar{R}_{1}$ by equations (31) and (23). Therefore, $J(R, w)<z(R, w)$ for all feasible $(R, w)$, which means that the locus $J=0$ lies above $z=0$. Figure 4 illustrates.

We conclude that unconstrained equilibrium sequences lie on that segment of the unconstrained manifold $\psi_{u}$ of the commitment economy defined in Theorem 2, which satisfies the incentive constraint $J \leq 0$ for the young, and $z \geq 0$ for the middle aged. In an economy without commitment, the unconstrained manifold exists only for initial values $w_{1} \in\left(\bar{w}_{1}, \bar{w}_{2}\right)$ of the debt load, as shown in Figure 4 , such that $0<\bar{w}_{1}<\bar{w}_{2}<y_{1}$. One easily shows that $\bar{w}_{1}<w^{*}<\bar{w}_{2}$, which proves Part 3 .

\section{A.6 Proof of Theorem 6}

Part 1 is obvious; parts 2, 3, and 4 are less so. Equilibrium sequences with tight debt constraints for each $t=1,2, \ldots$ solve the dynamical system of equations (32) and (12), subject to the solvency constraints (18), (19). The steady states of this system are easily shown to possess monotone convergence properties: $\left(0, \bar{R}_{1}\right)$ is a source and $\left(w^{*}, R_{c}^{*}\right)$ a saddle. To study in more detail the equilibrium manifold $\psi_{c}$, we define three auxiliary functions

$$
\begin{gathered}
M(R, w) \equiv B(R, R)+\frac{z(R, w)}{1+n} \\
N(R, w) \equiv-\frac{w}{R}+\frac{z(R, w)}{1+n} \\
Q(R, w) \equiv \frac{f(R)}{R}+\frac{z(R, w)}{1+n} .
\end{gathered}
$$

Note first that $R<R^{*} \rightarrow m(R)>R \rightarrow f(m(R))<f(R) \rightarrow f(m(R)) / R=$ $B(R, m(R))>B(R, R) \rightarrow Q(R, w)>J(R, w)>M(R, w)$ for all incentive-compatible pairs $(R, w)$. By the same token, $R>R^{*} \rightarrow Q(R, w)<J(R, w)<M(R, w)$ for all incentive-compatible $(R, w)$. In addition, the equations $M=0, N=0<Q=0$ describe upward sloped loci. Therefore we have:

1. If $R<R^{*}$, then the locus $Q(R, w)=0$ lies below $J(R, w)=0$, and $M(R, w)=0$ lies above $J(R, w)=0$ for all $(R, w) \in\left(\bar{R}_{1}, \infty\right) \times\left(0, y_{1}\right)$.

2. If $R>R^{*}$, then $Q=0$ lies above $J=0$, and $M=0$ lies below $J=0$ for all $(R, w) \in\left(\bar{R}_{1}, \infty\right) \times\left(0, y_{1}\right)$. 
3. $Q\left(\bar{R}_{1}, 0\right)=N\left(\bar{R}_{1}, 0\right)=0$

4. The loci $Q(R, w)=0$ and $N(R, w)=0$ lie above $z(R, w)=0$.

5. $Q=0$ lies below $N=0$ if, and only if, $R<R_{c}^{*}$ and $w<w_{c}^{*} \equiv-f\left(R_{c}^{*}\right)$.

Equations (12) and (32) require that the upward-sloped constrained equilibrium manifold $\psi_{c}$ lie between the loci $N=0$ and $Q=0$. This manifold intersects the solvency constraint $J=0$ at some point $\left(\bar{w}_{c}, \bar{R}_{c}\right)$ such that $\bar{R}_{c}>R^{*}$ and $\bar{w}_{c}>-f\left(R^{*}\right) \equiv w^{*}$. Hence, no constrained equilibrium exists for $w_{1}>\bar{w}_{c}$; a constrained equilibrium exists if $w_{1} \in\left(0, \bar{w}_{c}\right]$ and converges monotonically to the state $\left(\bar{w}_{c}, \bar{R}_{c}\right)$. Lastly, constrained equilibria exist for all initial conditions in the neighborhood of the critical point $\left(w^{*}, R^{*}\right)$. This completes the proof. 


\section{References}

[1] Aiyagari, R. (1994): "Uninsured Idiosyncratic Risk and Aggregate Saving," Quarterly Journal of Economics, 109, 659-84.

[2] Altonji, J., Hayashi, F. and Kotlikoff, L. (1982): "Is the Extended Family Altruistically Linked?" American Economic Review, 82, 1177-98.

[3] Alvarez, F. and Jermann, U. (2000): "Efficiency, Equilibrium, and Asset Pricing with Risk of Default," Econometrica, 68, 775-97.

[4] Araujo, A., Monteiro, P., and Pascoa, M. (1998): "Infinite Horizon Incomplete Markets with a Continuum of States," Mathematical Finance, 6, 119-32.

[5] Atkeson, A. and Lucas, R. (1992): "Efficient Distribution with Private Information," Review of Economic Studies, 59, 427-454.

[6] Attanasio, O. and Davis, S. (1996): "Relative Wage Movements and the Distribution of Consumption," Journal of Political Economy, 104, 1227-62.

[7] Attanasio, O. and Weber, G. (1993): "Consumption Growth, the Interest Rate and Aggregation," Review of Economic Studies, 60, 631-49.

[8] Attanasio, O. and Browning, M. (1995): "Consumption over the Life Cycle and over the Business Cycle," American Economic Review, 85, 1118-37.

[9] Azariadis, C., Bullard, J. and Ohanian, L. (2001): "Trend-Reverting Fluctuations in the Life-Cycle Model," forthcoming in Journal of Economic Theory.

[10] Bewley, T. (1986): "Dynamic Implications of the Form of the Budget Constraint," in Models of Models of economic dynamics, ed. by Hugo Sonnenschein, Springer Verlag.

[11] Bulow, J. and Rogoff, K. (1989): "Sovereign Debt: Is to Forgive to Forget?" American Economic Review, 79, 43-50.

[12] Campbell, J. and Mankiw, G. (1989): "Permanent Income, Current Income, and Consumption," in Olivier J. Blanchard and Stanley Fischer, eds. NBER Macroeconomic Annual. Cambridge, MA: MIT Press, 185-216.

[13] Chatterjee, S., Corbae, D., Nakajima, M. and Rios-Rull, J. (2002): "A Quantitative Theory of Unsecured Consumer Credit with Risk of Default," Working Paper no. 02-6, Federal Reserve Bank of Philadelphia. 
[14] Cole, H. and Kocherlakota, N. (1997): "Efficient Allocations With Hidden Income and Hidden Storage," Technical Report 238, Federal Reserve Bank of Minneapolis.

[15] Constantinides, G., Donaldson, J. and Mehra, R. (1997): "Junior Can’t Borrow: A New Perspective on the Equity Premium Puzzle," manuscript.

[16] Dubey, P., Geanakoplos, J. and Shubik, M. (1995): "Default and Efficiency in a General Equilibrium Model with Incomplete Markets," manuscript.

[17] Flavin, M. (1981): "The Adjustment of Consumption to Changing Expectations about Future Income," Journal of Political Economy, 89, 974-1009.

[18] Hall, R. E. and Mishkin, F. (1982): "The Sensitivity of Consumption to Transitory Income: Estimates from Panel Data on Households," Econometrica, 50, 461-82.

[19] Hansen, L., and Singleton, K. (1982): "Generalized Instrumental Variable Estimation of Nonlinear Rational Expectations Models," Econometrica, 50, 1269-86.

[20] Hansen, L., and Singleton, K. (1983): "Stochastic Consumption, Risk Aversion and the Temporal Behavior of Asset Returns," Journal of Political Economy, 91, 249-65.

[21] Jappelli, T. and Pagano, M. (1994): "Saving, Growth and Liquidity Constraints," Quarterly Journal of Economics, 108, 83-109.

[22] Kehoe, P. and Perri, F. (2000): "International Business Cycle with Endogenous Incomplete Markets," NBER Working Paper 7870.

[23] Kehoe, T. and Levine, D. (1985): "Comparative Statics and Perfect Foresight in Infinite Horizon Economies," Econometrica, 53, 433-54.

[24] Kehoe, T. and Levine, D. (1993): "Debt-Constrained Asset Markets," Review of Economic Studies, 60, 865-88.

[25] Kehoe, T. and Levine, D. (2001): "Liquidity Constrained Markets versus Debt Constrained Markets," Econometrica, 69, 575-98.

[26] Kehoe, T., Levine, D., Mas-Colell, A. and Woodford, M. (1991): "Gross Substitutability in Large-Square Economies," Journal of Economic Theory, 54, 1-25.

[27] Kiyotaki, N. and Moore, J. (1997): "Credit Cycles," Journal of Political Economy, 105, 211-248. 
[28] Kocherlakota, N. (1996): "Implications of Efficient Risk Sharing Without Commitment," Review of Economic Studies, 63, 595-609.

[29] Lambertini, L. (1998): "Borrowing and Lending without Commitment and with Finite Life," manuscript.

[30] Mankiw, G., Rotemberg, J. and Summers, L. (1985): "Intertemporal Substitution in Macroeconomics," Quarterly Journal of Economics, 100, 225-53.

[31] Phelan, C. and Townsend, R. (1991): "Computing Multi-Period, Information Constrained Optima," Review of Economic Studies, 58, 853-81.

[32] Runkle, D. (1991): "Liquidity Constraints and the Permanent Income Hypothesis: Evidence from Panel Data," Journal of Monetary Economics, 27, 73-98.

[33] Storesletten, K., Telmer, C. and Yaron, A. (2000): "Consumption and Risk Sharing Over the Life Cycle," manuscript.

[34] Woodford, M. (1988): "Stationary Sunspot Equilibria in a Finance-Constrained Economy," Journal of Economic Theory, 40, 128-37.

[35] Zeldes, S. (1989): "Consumption and Liquidity Constraints: An Empirical Investigation," Journal of Political Economy, 97, 305-46. 


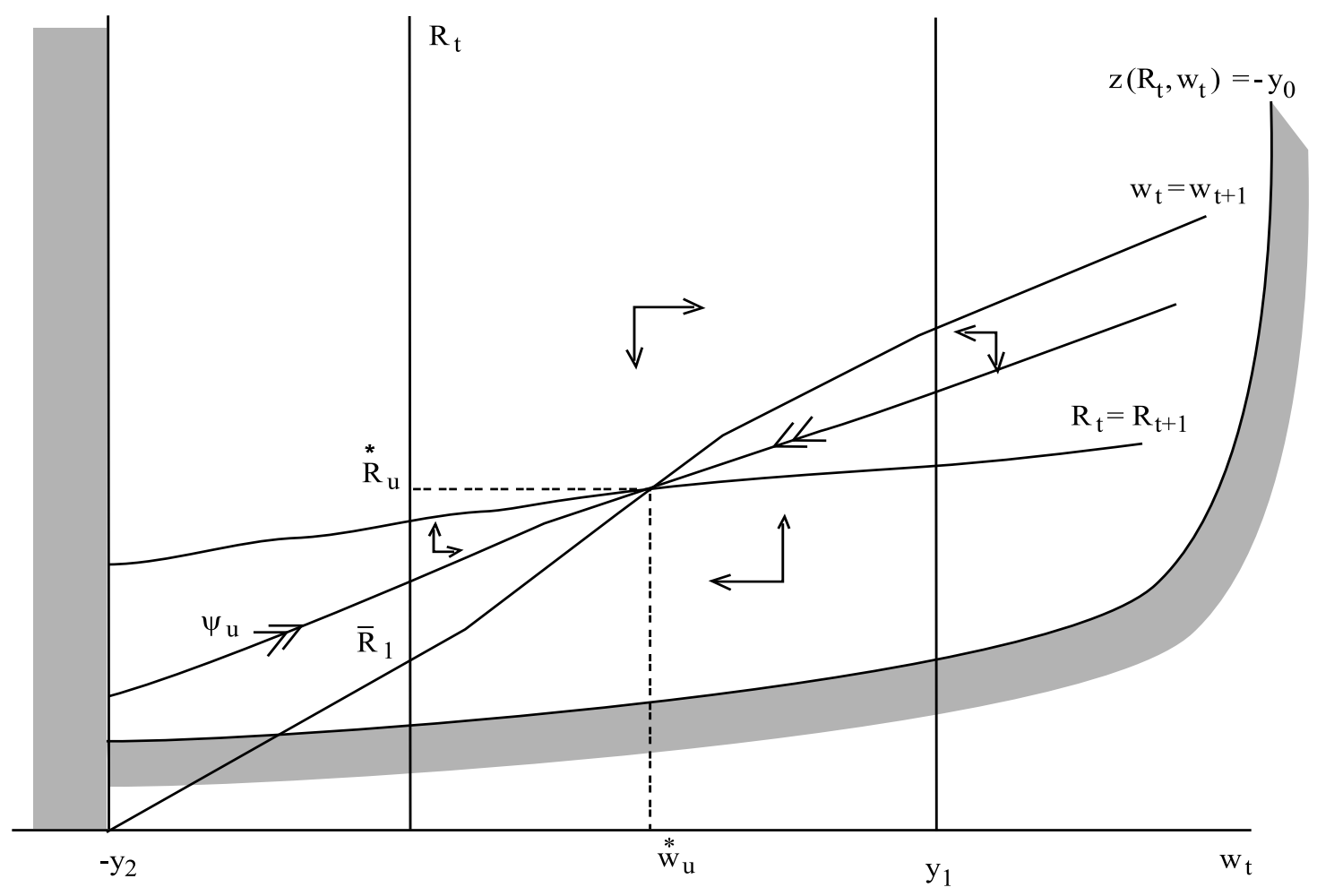

Figure 1: The equilibrium manifold of the commitment economy

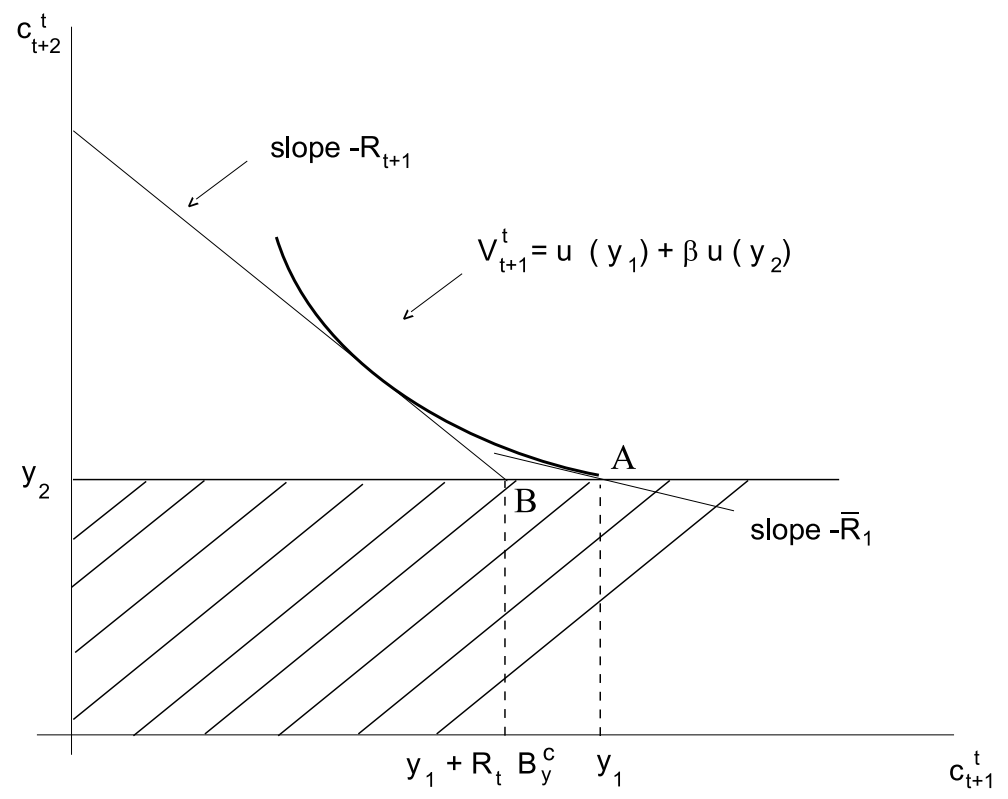

Figure 2: Individual rationality constraints for cohort $t$ 


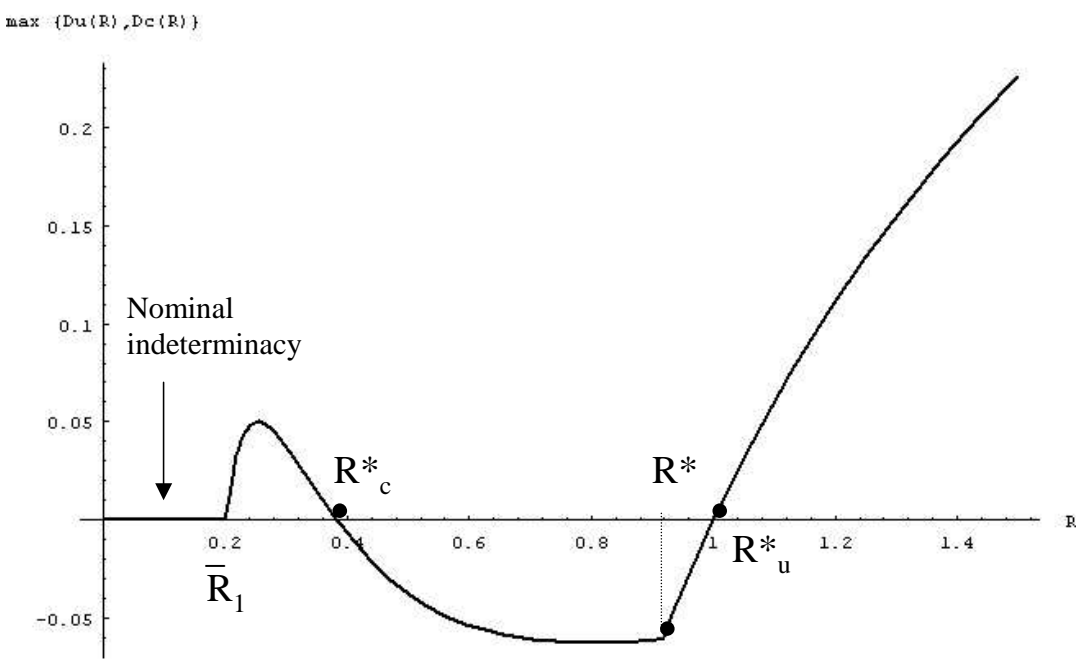

Figure 3: Stationary community asset demand

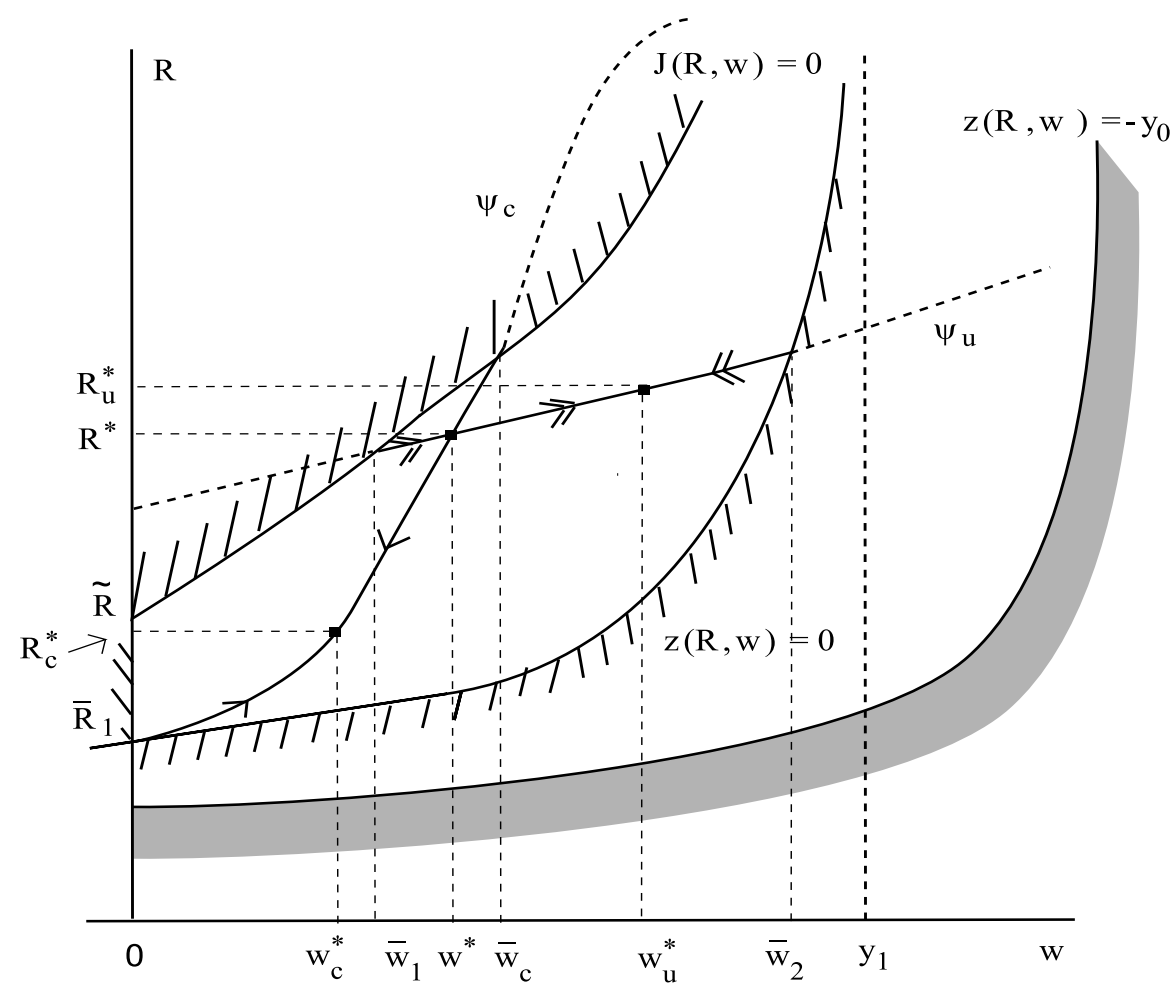

Figure 4: Dynamic equilibria for $\left(\beta, y_{1} / y_{0}, y_{1} / y_{2}\right)$ large, $\sigma$ small 


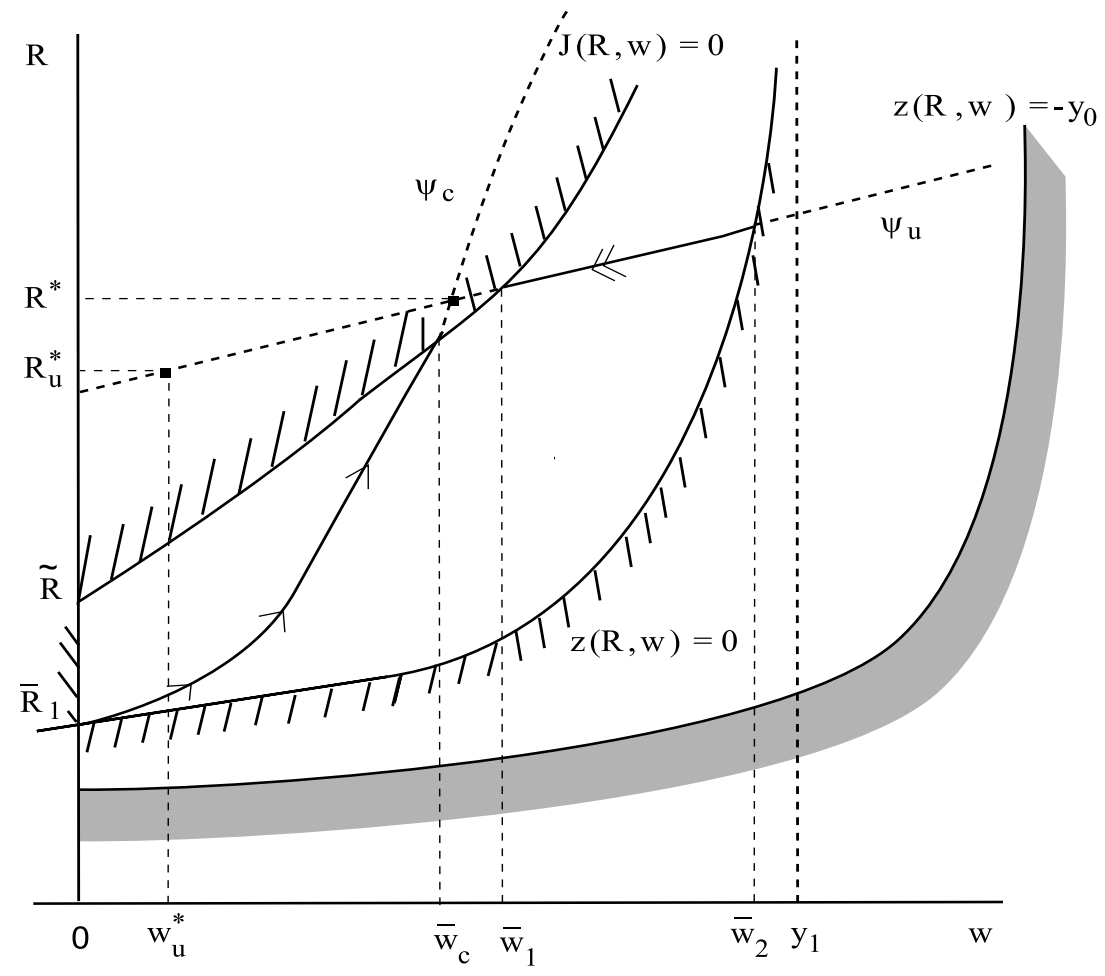

Figure 5: Dynamic equilibria for $\left(\beta, y_{1} / y_{0}, y_{1} / y_{2}\right)$ small, $\sigma$ large

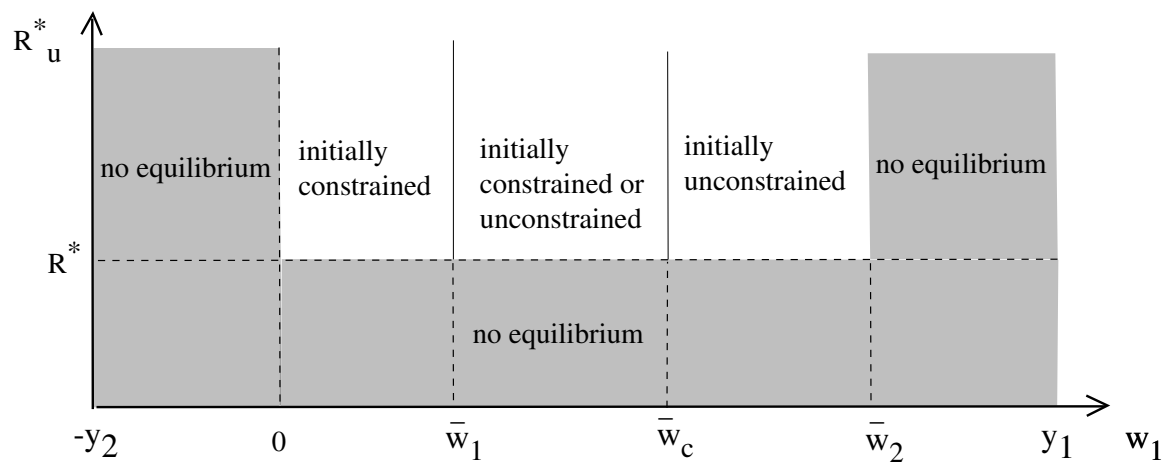

Figure 6: Regimes of dynamic equilibria 